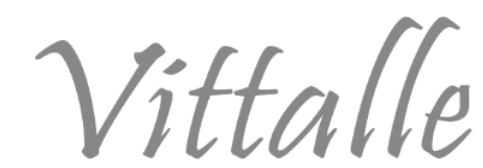

\title{
Um novo olhar para o tratamento do transtorno depressivo maior: uma revisão dos estudos clínicos realizados com cetamina e escetamina
}

\author{
Layza Kowalski $^{\mathrm{a}^{*}}$, Eslen Delanogare ${ }^{\mathrm{b}}$, Tiago Bittencourt de Oliveira ${ }^{\mathrm{a}}$ \\ ${ }^{a}$ Departamento de Ciências da Saúde, Universidade Regional Integrada do Alto Uruguai e das Missões - URI, Santo \\ Ângelo, RS, Brasil \\ ${ }^{\text {b }}$ Programa de Pós-Graduação em Neurociências, Neuroscience Coworking Lab - Universidade Federal de Santa \\ Catarina - UFSC, Florianópolis, SC, Brasil
}

Histórico do Artigo

Recebido em:

23/06/2021

Aceito em:

29/09/2021

\section{Palavras-chave:}

Transtornos do humor; psicotrópicos; antidepressivos
Keywords:

Mood disorders; psychotropic drugs; antidepressive agents

\begin{abstract}
RESUMO
O tratamento do transtorno depressivo maior consiste, principalmente, na psicoterapia, terapia somática e farmacoterapia. Esta, inclui majoritariamente fármacos que atuam no sistema monoaminérgico. Apesar da sua eficácia terapêutica, esta classe de antidepressivos requer várias semanas para ter seus efeitos terapêuticos, representando um grande desafio para o manejo de paciente com depressão severa e em risco de suicídio. O objetivo do estudo foi revisar os estudos clínicos abordando a molécula de cetamina, e seu enantiômero escetamina, no tratamento do transtorno de depressão maior, a fim de verificar sua eficácia terapêutica, segurança e tolerabilidade. Trata-se de uma revisão integrativa, de estudos que apresentem a cetamina ou escetamina como agente antidepressivo, nas bases de dados U.S. National Library of Medicine e ClinicalTrials.gov. Estudos envolvendo a cetamina intravenosa demonstraram uma eficácia antidepressiva rápida, com pacientes atingindo os critérios de resposta em até um dia após a administração do ativo. Ainda, observou-se também, a rápida diminuição nos níveis de ideação suicida. Entretanto, a fim de facilitar a administração, estudos sugeriram o uso da via intranasal, que se mostrou bem tolerada. Ademais, com evidências propondo uma maior afinidade da escetamina com receptores N-metil-D-aspartato, o isolamento desta permitiu uma maior eficácia terapêutica antidepressiva, além de um prolongamento na manutenção do efeito. Porém, a escetamina provocou efeitos adversos de severidades variadas, incluindo dissociação, sonolência, parestesia, tontura, vertigem, ansiedade, delírio e tendência suicida. Cetamina e escetamina mantém-se como medicamentos de alto risco, devido aos seus efeitos adversos de severidades variadas, incluindo dissociação, sonolência, parestesia, tontura, vertigem, ansiedade, delírio e tendência suicida. Ainda, se faz necessário atentar-se à melhor via de administração para cada caso em particular, com a via intravenosa para pacientes com ideação suicida (pelos rápidos efeitos antidepressivos) e intranasal em casos de depressão moderada.
\end{abstract}

A new look at the treatment of major depressive disorder: a review of clinical studies performed with ketamine and esketamine

\begin{abstract}
The treatment of major depressive disorder consists mainly of psychotherapy, somatic therapy and pharmacotherapy. This mainly includes drugs that act in the monoaminergic system. Despite its therapeutic efficacy, this class of antidepressants requires several weeks to have its therapeutic effects, representing a great challenge for the management of patients with severe depression and at risk of suicide. The aim of the study was to review clinical studies addressing the ketamine molecule, and its esketamine enantiomer, in the treatment of major depression disorder, in order to verify its therapeutic efficacy, safety and tolerability. This is an integrative review of studies presenting ketamine or esketamine as an antidepressant agent in the U.S. National Library of Medicine and ClinicalTrials.gov. Studies involving intravenous ketamine demonstrated rapid antidepressant efficacy, with patients meeting the response criteria within one day of active administration. Furthermore, the rapid decrease in levels of suicidal ideation was also observed. However, in order to facilitate administration, studies suggested the use of the intranasal route, which proved to be well tolerated. Furthermore, with evidence proposing a greater affinity of esketamine with $\mathrm{N}$-methyl-D-aspartate receptors, its isolation allowed a greater efficacy of antidepressant therapy, in addition to a prolongation in the maintenance of the effect. However, esketamine caused adverse effects of varying severities, including dissociation, drowsiness, paresthesia, dizziness, vertigo, anxiety, delirium, and suicidal tendency. Ketamine and esketamine remain high-risk medicines due to their adverse effects of varying severities, including dissociation, drowsiness, paresthesia, dizziness, vertigo, anxiety, delirium and suicidal tendency. Furthermore, it is necessary to pay attention to the best route of administration for each particular case, with intravenous route for patients with suicidal ideation (by its rapid antidepressant effects) and intranasal in cases of moderate depression.
\end{abstract}

\footnotetext{
*Autor correspondente: layzakowalski@hotmail.com (Kowalski L.)
} 


\section{Introdução}

\section{Transtorno de Depressão Maior}

A depressão é a principal causa de incapacidade em todo o mundo (1). Caracterizada principalmente por humor deprimido e perda na capacidade de sentir prazer, pode também gerar sentimento de culpa e desvalorização, e em casos graves, tendências suicidas $(2,3)$. Estimativas da Organização Mundial de Saúde (OMS) mostram que, em 2017, 322 milhões de pessoas conviviam com depressão no mundo. No mesmo período, no território brasileiro, 11,5 milhões de casos de depressão foram identificados, representando 5,8\% da população total (4). Embora a depressão tenha uma alta prevalência, sua etiologia não é totalmente compreendida (5). Dentre as principais hipóteses neurobiológicas relacionadas ao transtorno depressivo, estão: a hipótese genética (6); Gabaérgica (ácido gama-aminobutírico) $(7,8)$; do ciclo circadiano (9); da disfunção do eixo hipotálamopituitária-adrenal (HPA) (10); da disfunção metabólica (11); monoaminérgica (12); glutamatérgica (13); e neurotrófica (14).

O tratamento do transtorno depressivo maior (TDM), um subtipo da depressão, caracterizado pela sua resistência e difícil remissão, consiste, principalmente, na psicoterapia, terapia somática e farmacoterapia (15). Esta última, amplamente mencionada nos guias terapêuticos e protocolos clínicos de manejo da depressão, inclui majoritariamente os fármacos antidepressivos (16). Estes psicotrópicos são comumente os inibidores seletivos de receptação de serotonina (ISRSs), inibidores de recaptação de serotonina e noradrenalina (ISRSNs), inibidores da monoamina oxidase (IMAOs) e os antidepressivos tricíclicos (ADTs) (17). O mecanismo primário dessas drogas é a atuação nos sistemas de neurotransmissão monoaminérgico, gerando o aumento da concentração sináptica de serotonina, norepinefrina e dopamina (15). No entanto, estes fármacos requerem um período de duas a quatro semanas de tratamento contínuo para produzir efeito terapêutico em pacientes deprimidos, o que pode prolongar os sintomas depressivos, bem como aumentar o risco de suicídio (18). Além disso, uma parte significativa dos pacientes não conseguem atingir a remissão completa (16), levando em consideração que os antidepressivos convencionais não são capazes de produzir uma remissão bem-sucedida em cerca de 60 a $70 \%$ dos pacientes com uma única prova terapêutica de 8 a 12 semanas, e cerca de 20 a 30\% destes pacientes não atingem a remissão nem com estratégias de aumento sequencial ou mudança de fármacos (19). Ainda, no caso do tratamento convencional com ISRSs, por exemplo, o aumento da atividade serotoninérgica está comumente associado a efeitos adversos (náusea, diarreia, diminuição da função e interesses sexuais, cefaleias, alterações no sono e no peso), o que pode levar os pacientes a não persistirem o tratamento (19).

Apesar de a saúde mental ser uma área que exige grande demanda de novos fármacos, esta tem sido gradualmente mais desatendida de uma perspectiva de investimento por boa parte da indústria farmacêutica global, e, por conseguinte, a capacidade de tratá-la segue sendo um desafio (20). Essa limitação se dá pelas dificuldades e barreiras encontradas no desenvolvimento de novas drogas que atuem no sistema nervoso central (SNC), seja pela complexidade deste, seja pela falta de compreensão da base molecular de muitos distúrbios, ou ainda pela indefinição da patologia ou o custoso diagnóstico preciso (21).

Levando em consideração as características dos antidepressivos atuais, nota-se a necessidade na descoberta de novos antidepressivos com início mais rápido e maior eficácia, em pacientes que apresentam diagnóstico de transtorno depressivo maior, para que os sintomas, a disfunção e o risco de suicídio sejam minimizados (22). Logo, a divulgação dos resultados do presente estudo, em um âmbito nacional, torna-se imprescindível para um maior entendimento do processo de descoberta e testagem de 
fármacos psicotrópicos inovadores, como a cetamina e/ou escetamina.

O presente estudo tem como objetivo revisar os estudos clínicos realizados com as moléculas de cetamina e escetamina em humanos, utilizados no tratamento do transtorno de depressão maior e/ou depressão resistente ao tratamento, a fim de documentar sua eficácia terapêutica, segurança/tolerabilidade assim como o seu rápido início de ação antidepressiva e a melhor via de administração.

\section{Cetamina}

Sob nomenclatura 2 - (2 - clorofenil) - 2 - (metilamino) ciclohexan - 1 - ona (23), a molécula de cetamina possui dois isômeros ópticos: $\mathrm{S}(+)$ cetamina (escetamina) e R (-) cetamina (arcetamina) (Figura 1). Sua forma racêmica (50\% de cada enantiômero), é comumente comercializada como um fármaco anestésico e analgésico (24), por apresentar segurança e tolerabilidade (22). Ainda, em doses sub-anestésicas, ocorre o seu uso off-label como uma substância de recreação (22).

A

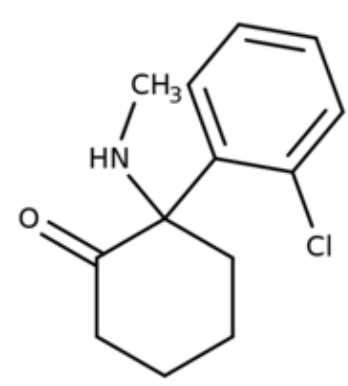

B

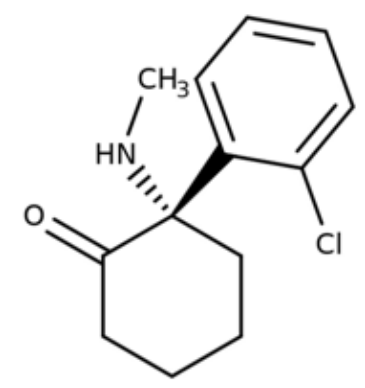

C

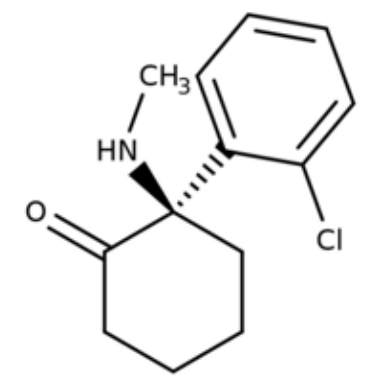

Figura 1 - Molécula de cetamina e seus isômeros ópticos. Cetamina (A) em sua forma racêmica (mistura de dois isômeros opticamente ativos, a escetamina [B] e arcetamina [C]). PubChem CID: $3821(23)$.

O cenário farmacoterapêutico da depressão tem sofrido mudanças desde a apresentação desta substância, denominada cetamina, com imediato e prolongado caráter antidepressivo (25). Trata-se de um fármaco atuante no sistema glutamatérgico, que tem surgido como uma potencial solução para as limitações dos modelos de tratamento atuais para o TDM (26).

\section{Modelos Animais: estudos mecanicistas}

O glutamato, neurotransmissor essencial do principal sistema excitatório do SNC, o sistema glutamatérgico, é sintetizado a partir da desaminação da glutamina, pela enzima glutaminase, sendo armazenado em vesículas, liberadas em dependência do potencial de ação. Este neurotransmissor, quando liberado na fenda sináptica, pode interagir com dois tipos de receptores de membrana, classificados farmacologicamente em ionotrópicos ou metabotrópicos $(7,27)$. Os primeiros incluem os receptores $\mathrm{N}$-metil-D-aspartato (NMDA), alfa-amino-3-hidroxi-metil-5-4-isoxazolpropiónico (AMPA) e cainato, enquanto os segundos incluem uma família de receptores $\left(m_{G l u R_{1}}\right.$ a $\left.m_{G l u R}\right)$ acoplados às proteínas $\mathrm{G}$ (27). O glutamato, apesar de ser essencial para o desenvolvimento dendrítico e neuronal (28), em excesso é excitotóxico aos neurônios, ou seja, causa danos ou morte celular (22). Ainda, há evidências de que esta elevação nos níveis de glutamato 
esteja relacionada com o surgimento dos sintomas depressivos, fortalecendo a ideia de que este neurotransmissor desempenha um importante papel na fisiopatologia da depressão, posto isto, conclui-se a chamada hipótese glutamatérgica (29).

A hipótese glutamatérgica sustenta-se desde a década de 1990, quando estudos demonstraram que antagonistas dos receptores de NMDA (NMDAr) diminuem o tempo de imobilidade no teste do nado forçado em camundongos, o que sugeriu um efeito tipoantidepressivo destas substâncias (13).

No caso da cetamina, sugere-se que o mecanismo de ação tenha início a partir do bloqueio, tanto de NMDAr de uma subpopulação de interneurônios GABAérgicos (via A) $(30,31)$, assim como de NMDAr extrassinápticos do neurônio glutamatérgico póssináptico (via B) (32). A via A, também chamada de hipótese de desinibição, após o antagonismo do NMDAr, gera-se uma diminuição nos níveis intracelulares de $\mathrm{Cl}^{-}$e um aumento nos níveis de $\mathrm{Mg}^{2+}$ (aumento este causado pela despolarização da membrana e liberação de $\mathrm{Mg}^{2+}$ antagonista dos NMDAr) (31), "desbloqueando" neurônios glutamatérgicos (por meio da inibição do sistema GABAérgico), e a consequente liberação de glutamato (Glu) na fenda sináptica no córtex pré-frontal (32). Em outras palavras, o antagonismo dos NMDAr leva a uma inibição das ações do sistema GABAérgico sobre o tônus glutamatérgico, diminuindo os níveis do neurotransmissor GABA, acarretando na liberação de vesículas sinápticas contendo Glu (32). O Glu liberado na fenda sináptica é capaz de promover a ativação preferencial de receptores ácido alfa-amino-3-hidroxi-5-metil-4-isoxazol-propiônico (AMPAr) (33), que por sua vez, causam um rápido influxo de íons de sódio $\left(\mathrm{Na}^{+}\right)$, levando à despolarização da membrana e ativação de canais de cálcio dependentes de voltagem (CCVD) $(34,35)$. Os CCVD permitem o influxo de $\mathrm{Ca}^{2+}$, que induzem a liberação do fator neurotrófico derivado do encéfalo (BDNF) na fenda sináptica (36).

O bloqueio dos NMDAr extrassinápticos (via B), mediado pela cetamina, é capaz de desinibir o fator de alongamento eucariótico 2 (eEF2), aumentando (assim como a via A), a tradução do BDNF $(32,33)$. Essa liberação de BDNF desencadeia a ativação do receptor de tropomiosina quinase $\mathrm{B}$ (TrkB), levando à fosforilação e ativação de quinases reguladas por sinal extracelular (ERKs), proteína quinase B (PKB/Akt) e supressão da glicogênio sintase quinase 3 (GSK-3).

Esses eventos culminam na ativação da proteína alvo mecanístico da rapamicina (mTOR), (37) que está envolvida no aumento da síntese proteica, sinaptogênese e por consequência, rápida ação antidepressiva (32,37-39). Interessantemente, estudos clínicos têm reforçado a premissa que o rápido efeito antidepressivo desencadeado pela administração de cetamina está associado ao aumento da conectividade do córtex préfrontal e a modulação da mTOR. O mecanismo de ação da cetamina é representado na Figura 2. 


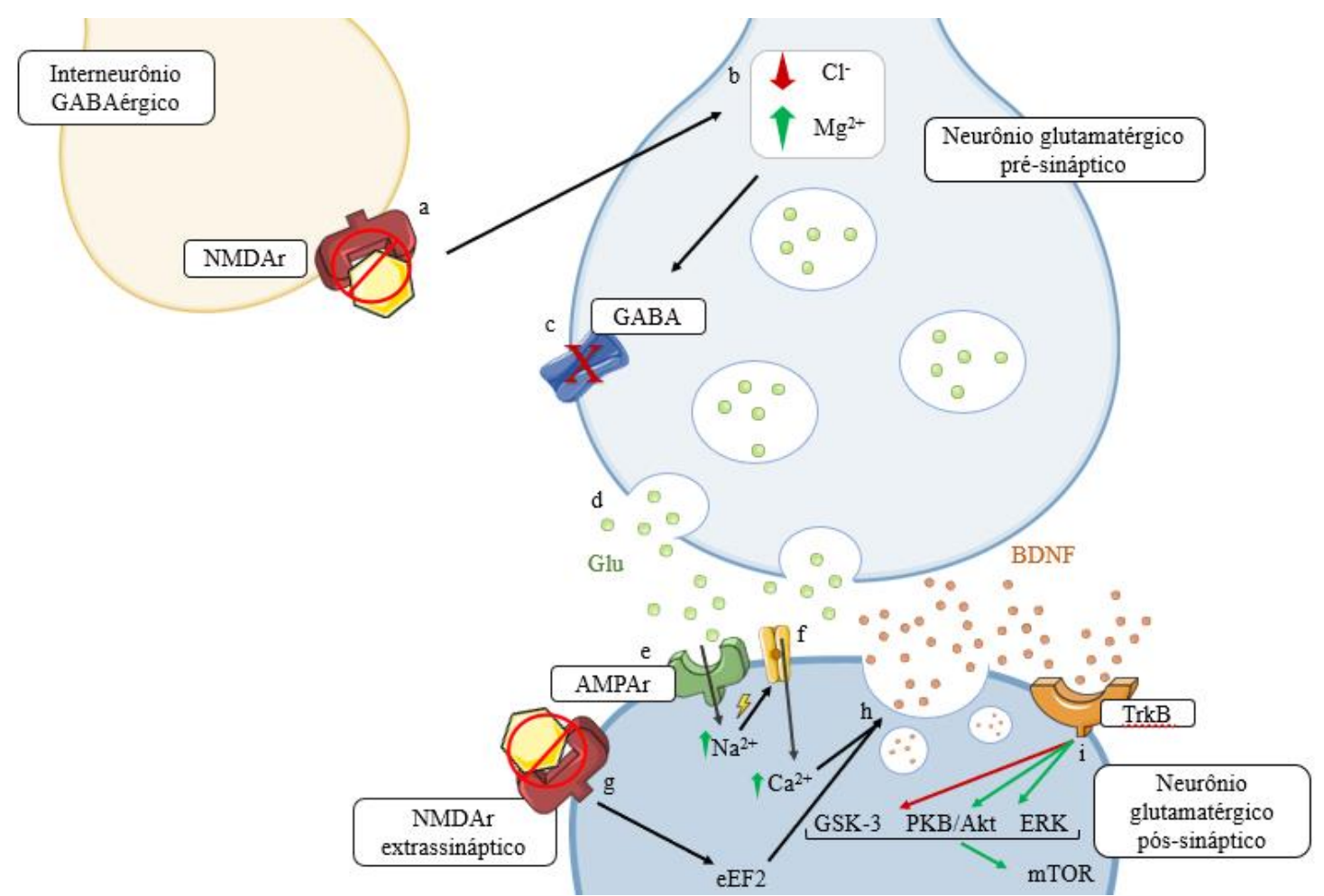

Figura 2 - Mecanismo de ação da cetamina no sistema nervoso central de humanos. O mecanismo da ação antidepressiva da cetamina tem seu início, em teoria, quando (a) esta antagoniza os NMDAr, em interneurônios GABAérgicos. Esse bloqueio (b) gera uma diminuição intracelular do influxo de íons de cloreto e um aumento de íons de magnésio, (c) causando a desinibição de neurônios piramidais, e consequente (d) liberação de vesículas, contendo o NT Glu, na fenda sináptica. (e) Glu, por sua vez, ativa AMPAr, que será capaz de elevar o influxo de sódio, gerando a despolarização da célula. Esta, (f) ativa os CCDV, permitindo a entrada de cálcio no interior da célula. (g) Os NMDAr extra sinápticos, também antagonizados pela molécula de cetamina, causam a desinibição do eEF2, que assim como o acúmulo de cálcio proporcionado pelos CCDV, irão estimular a (h) liberação de vesículas contendo BNDF, na fenda sináptica. O BNDF agora estará apto a ser um agonista do TrkB, que (i) poderá levar à fosforilação e ativação de ERK, PKB/Akt e à supressão de GSK-3. Estes eventos estão envolvidos na ativação de mTOR, responsável, em partes, pelo ciclo do AMPA, aumento da síntese proteica, sinaptogênese e por consequência, da rápida ação antidepressiva.

Abreviaturas: NMDAr: receptor de N-metil-D-aspartato; GABA: Ácido $\gamma$-aminobutírico; NT: neurotransmissor; Glu: glutamato; AMPAr: receptor de alfa-amino-3-hidroxi-metil-5-4isoxazolpropiónico; CCDV: canais de cálcio voltagem-dependente; eEF2: fator de alongamento eucariótico 2; BDNF: fator neurotrófico derivado do encéfalo; TrkB: receptor tropomiosina cinase B; ERK: quinases reguladas por sinal extracelular; PKB/Akt: proteína quinase B; GSK-3: glicogênio sintase quinase 3; mTOR: proteína alvo mecanístico da rapamicina.

Figura esquematizada com arquivos de propriedade do banco de imagens "Servier Medical Art".

\section{Métodos}

Trata-se de uma revisão integrativa, com o objetivo de documentar a eficácia 
terapêutica, segurança/tolerabilidade e a melhor via de administração das moléculas de cetamina, e seu enantiômero escetamina, ambas utilizadas no tratamento do transtorno de depressão maior e/ou depressão resistente ao tratamento.

A revisão integrativa é uma abordagem metodológica que permite a inclusão de estudos experimentais e não-experimentais para uma compreensão completa do fenômeno analisado. Reúne dados da literatura, incorporando definição de conceitos, revisão de teorias e evidências, e análise de problemas metodológicos de um tópico em particular (40).

Para a realização do estudo, foram percorridas fases como a identificação do tema e seleção da hipótese, estabelecimento de critérios para inclusão e exclusão de estudos, assim como a busca na literatura, categorização e avaliação dos estudos incluídos, interpretação dos resultados e redação do conhecimento evidenciado (41).

Para a seleção dos estudos clínicos, utilizou-se a base de dados fornecida pela PUBMED, o ClinicalTrials.gov, que armazena ensaios privados e públicos conduzidos em todo o mundo. Para a seleção dos artigos científicos contendo resultados de ensaios clínicos, mas que por algum viés de pesquisa não foram encontrados no clinicaltrials. gov, utilizou-se a bases de dados U.S. National Library of Medicine (PUBMED).

A fim de buscar evidências que respondam à questão da pesquisa, foram selecionados os termos "major depressive disorder", "treatment-resistent depression", "psychotropic drugs", "antidepressive agents", "ketamine" e "esketamine", combinados por meio dos operadores booleanos AND e $O R$.

O levantamento bibliográfico contemplou artigos publicados até o ano de 2021. Os critérios para inclusão das publicações foram: 1) artigos publicados em português e inglês; 2) estudos que tragam a cetamina e/ou escetamina como agente antidepressivo; 3) ensaios clínicos de fase 3 ou 4 . Os critérios de exclusão foram: 1) estudos com células; 2) estudos com animais não humanos. Na figura 3, observa-se a etapa de busca e seleção de estudos.

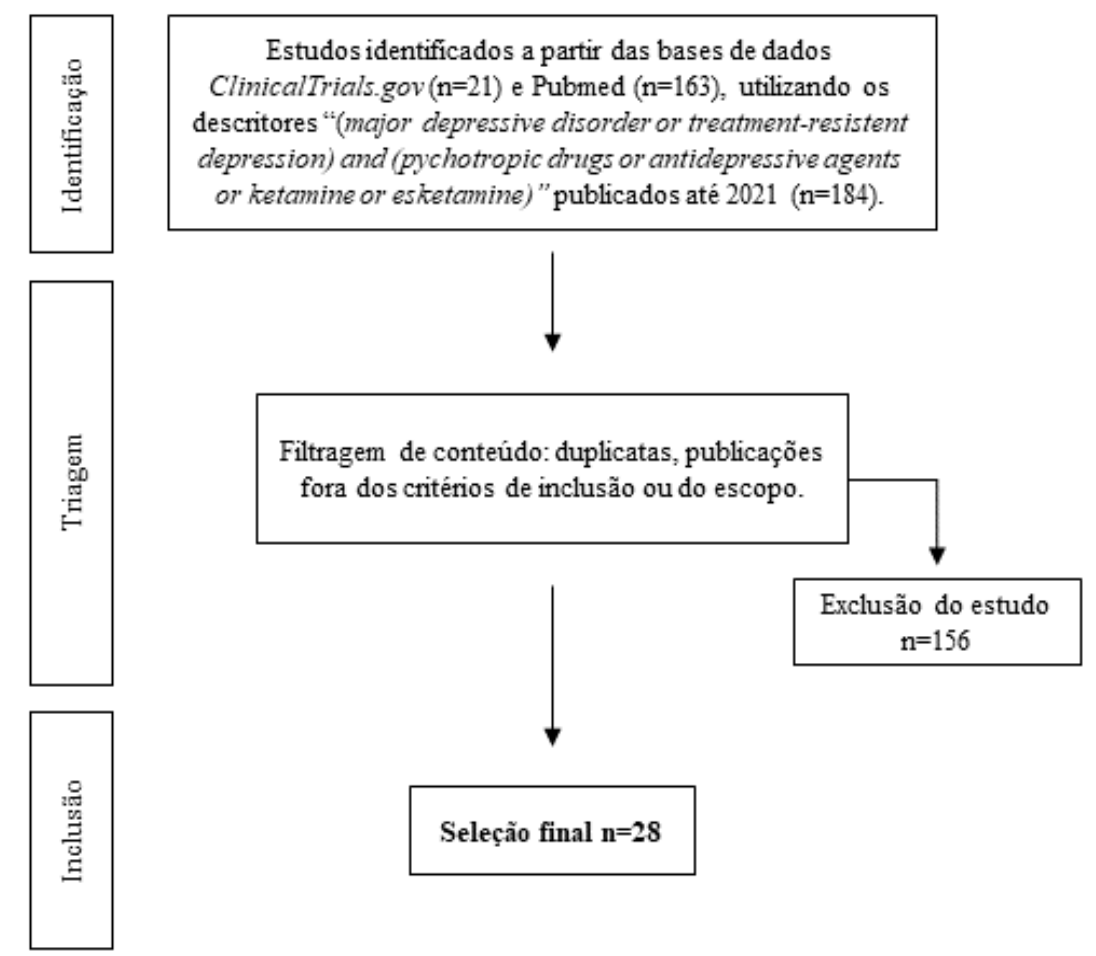

Figura 3 - Fluxograma da etapa de busca e seleção de estudos a integrar a presente revisão. 


\section{Resultados e discussão}

\section{Ensaios clínicos com a cetamina enquanto agente antidepressivo}

O primeiro estudo envolvendo a cetamina enquanto um agente terapêutico no transtorno depressivo maior, foi conduzido em 2000, por Berman et al. (25), no Departamento de Psiquiatria da Universidade Yale, em New Haven, CT, EUA. Tratou-se de um estudo controlado, cruzado, randomizado e duplo-cego, com o objetivo de verificar a existência do efeito antidepressivo em oito pacientes, que receberam $0,5 \mathrm{mg} / \mathrm{kg}$ IV de cloridrato de cetamina, por 40 minutos, ou placebo inativo (solução salina). Os resultados mostraram uma melhora dos sintomas depressivos apenas quatro horas após a administração de cetamina, e na metade da amostra, essa melhora ocorreu dentro de 72 horas após a infusão. Utilizaram como principal parâmetro de análise, a Escala de Avaliação de Hamilton para Depressão (HAMD), com uma diferença de 14 pontos $( \pm 10)$ em pacientes que receberam a cetamina e 0 pontos $( \pm 12)$ em pacientes que receberam placebo.

Em 2006, Zarate et al. (26), do Programa de Pesquisa Intramural do Instituto Nacional de Saúde Mental (NIMH), por meio de um estudo similar ao de Berman (25), controlado, cruzado, randomizado e quádruplo-cego, com pacientes diagnosticados com depressão refratária, e a partir de um mesmo objetivo, verificaram que aos 110 minutos após o tratamento (placebo inativo e $0,5 \mathrm{mg} / \mathrm{kg} \mathrm{IV}$ de cloridrato de cetamina, por 40 minutos, com uma semana de diferença), o ativo apresentou maior eficácia. Houve uma ampla diferença entre o efeito da cetamina e placebo $(d=1,46$ [intervalo de confiança de $95 \%$, 0,91-2,01] após 24 horas e $\mathrm{d}=0,68$ [intervalo de confiança de 95\%, 0,13-1,23] após 7 dias). Dos 17 pacientes tratados com a cetamina, $71 \%$ atenderam aos critérios de resposta antidepressiva e $29 \%$ aos critérios de remissão no dia seguinte à infusão. Trinta e cinco por cento dos sujeitos mantiveram a resposta por pelo menos uma semana. Os principais efeitos adversos que aconteceram após administração de cetamina foram distúrbios perceptivos, confusão, elevações na pressão arterial, euforia, tontura e aumento da libido. No grupo que recebeu placebo inativo, a irritação gastrointestinal, aumento da sede, dor de cabeça, gosto metálico e prisão de ventre foram mais presentes. A maior parte dos efeitos adversos cessaram após 80 minutos da infusão, e em nenhum caso os distúrbios perceptivos ou a euforia persistiram além de 110 minutos. Apesar disso, não houve eventos adversos graves durante o estudo (26).

Boa parte dos medicamentos antidepressivos atuais apresentam a limitação da demorada mudança sobre os pensamentos suicidas, e é a partir disso que, em 2009, Price et al. (42), por meio de um ensaio intervencional, sem placebo, fatorial, randomizado e triplo-cego, realizado na Escola de Medicina de Monte Sinai, avaliaram efeitos da cetamina intravenosa sobre os pensamentos suicidas. O fármaco, com dose 0,5 mg/kg, administrado por 40 minutos, serviu de tratamento para pacientes com depressão resistente ao tratamento (TRD), a fim de avaliar as medidas explícitas e implícitas do suicídio. Notou-se que, após o primeiro dia de uma única infusão de cetamina, os escores de comportamento suicida, avaliados pela Escala de Depressão de Montgomery e Asberg, índices de ideação suicida (MADRS-SI) diminuíram 2,08 pontos. Ainda, dos 13 pacientes com significante ideação suicida (MADRS-SI $\geq 4)$ anterior ao tratamento, oito $(62 \%)$ destes tiveram quase ou total melhora dos pensamentos (MADRS-SI 0 ou 1) e três (23\%) apresentaram algumas flutuações nos pensamentos (MADRS-SI 2 ou 3).

Autores $(25,26,42)$ comprovaram que uma única administração de cetamina IV é capaz de gerar uma rápida resposta antidepressiva, que se manteve por dias. Entretanto, após a remissão de sintomas depressivos, principalmente em pacientes resistentes à farmacoterapias anteriores, a recidiva é uma problemática importante. Como uma 
alternativa para a redução dos riscos de recidivas, assim como a diminuição dos efeitos adversos da cetamina, citados no estudo de Zarate (26), um estudo de Mathew et al. (43) controlado, fatorial, randomizado e triplo-cego, objetivou examinar a segurança e a eficácia da cetamina no tratamento de pacientes com transtorno depressivo maior resistente ao tratamento, tal como analisar a eficácia da lamotrigina (300mg ou placebo, 2 horas antes de receber cetamina IV) na redução dos efeitos colaterais potenciais associados à cetamina. Ainda, utilizou-se o riluzol (100-200mg/dia VO), um agente modulador de glutamato, sob a hipótese de que a sinergia mecanicista entre ambos fármacos (cetamina e riluzol) pudesse conferir proteção contra a recidiva do TDM. No entanto, mesmo com a pré-administração de lamotrigina, não houve uma redução significativa dos efeitos colaterais psicotomiméticos associados à cetamina, sendo reportado pelos pacientes as queixas de: visão turva, diminuição da nitidez mental, tontura/desmaio, sonolência, sensação estranha/irreal, dor de cabeça, dormência/formigamento, zumbido nos ouvidos/problemas de audição e fala arrastada. Da mesma maneira, não houveram diferenças significativas no tempo de recidiva entre os participantes que receberam riluzol ou placebo. Apesar destes dois resultados não esperados, a cetamina apresentou eficácia antidepressiva, corroborando com os estudos anteriormente realizados $(25,26,42)$.

Em 2010, ann Het Rot et al. (44), a partir de um estudo intervencional e aberto, não controlado e sem placebo, conduzido na Escola de Medicina de Monte Sinai, objetivou testar a tolerabilidade, segurança e eficácia da cetamina IV, em repetidas doses, em dez pacientes com TRD sintomáticos e sem medicação, que obtiveram anterior resposta terapêutica significativa com uma única dose de cetamina. Nove pacientes $(n=10)$ atingiram os critérios de resposta antidepressiva (redução $\geq 50 \%$ na escala MADRS) após a primeira infusão (às $24 \mathrm{~h}, 6,9 \pm 2,8$ ), bem como após a sexta infusão $(5,0 \pm 3,7)$. Dos nove pacientes que receberam as múltiplas doses de cetamina, oito tiveram recidivas, em média, 30 dias após a primeira infusão e 19 dias após a sexta infusão. Um paciente permaneceu em remissão por mais de três meses após o tratamento com cetamina. Em relação aos efeitos adversos, a cetamina provocou sintomas psicóticos mínimos positivos e três pacientes experimentaram dissociação significativa, mas transitória. Os efeitos colaterais durante e após cada infusão de cetamina foram geralmente leves (44).

Ainda em 2010, com apoio do Programa de Pesquisa Intramural do Instituto Nacional de Saúde Mental (NIMH), Diaz Granados et al. (45) examinaram os efeitos de uma única dose de cetamina $(0,5 \mathrm{mg} / \mathrm{kg} \mathrm{IV}$, por 40 minutos) em 33 sujeitos com ideação suicida e transtorno de depressão maior resistente ao tratamento, por meio de um estudo intervencional e aberto, não controlado e sem placebo. Dez indivíduos $(n=33)$ apresentaram alto escore na Escala para Ideação Suicida (SSI $\geq 4$ ) no pré-tratamento com cetamina, e estes demonstraram uma redução no escore após 40 minutos (nove $[n=10]$ ) e 80 minutos (um [n=10]) da infusão de ativo. Sintomas de depressão, ansiedade e desesperança foram significativamente reduzidos em todos os pontos de tempo $(p<0,001)(45)$.

É de conhecimento público que o suicídio (ou ideação suicida), acompanhados ou não de transtornos mentais, não possuem nenhum protocolo de manejo farmacoterapêutico em ambientes de emergência, que possa contribuir rapidamente para a melhora dos sintomas. Logo, levando em consideração a comprovada eficácia da cetamina IV nas medidas de suicídio (42), pesquisadores do departamento de emergência do Hospital Yale - New Haven, USA (46) examinaram a viabilidade, tolerabilidade e eficácia de uma única e rápida infusão (um a dois minutos) de cetamina ( $0,2 \mathrm{mg} / \mathrm{kg} \mathrm{IV})$ em pacientes deprimidos e com ideação suicida, atendidos no pronto-socorro. Os escores médios do MADRS caíram significativamente de $40,4( \pm 1,8)$ na pré-infusão de cetamina, para $11,5( \pm 2,2) 240$ minutos pós-infusão. Além disso, as pontuações na escala MADRS-SI também 
diminuíram significativamente, de $3,9( \pm 0,4)$ para $0,6( \pm 0,2)$, após 40 minutos da administração de cetamina. Essa melhoria permaneceu por pelo menos 10 dias (46).

Com um ensaio controlado, paralelo, randomizado e duplo-cego, em 2013, Murrough et al. (47) avaliaram a rápida eficácia antidepressiva da cetamina em um grande grupo de pacientes $(n=73)$ com depressão grave resistente ao tratamento. Um dos grupos de estudo recebeu uma única infusão de $0,5 \mathrm{mg} / \mathrm{kg}$ IV de cloridrato de cetamina, por 40 minutos, enquanto o grupo controle recebeu uma única infusão de $0,45 \mathrm{mg} / \mathrm{kg}$ de midazolam, administrado por via IV, durante 40 minutos. $\mathrm{O}$ grupo que recebeu cetamina apresentou maior redução na pontuação do MADRS, 24 horas após o tratamento, em comparação ao grupo controle, com uma diferença de 7,95 pontos (Intervalo de Confiança - IC de 95\%, 3,20 a 12,71) (47).

A fim de verificar se infusões seriadas, ou menores taxas de infusão, de cetamina intravenosa resultam em maior eficácia antidepressiva em pacientes com transtorno de depressão maior, Rasmussen et al. (48), pesquisadores de Rochester, Estados Unidos (EUA), em um estudo intervencional, aberto e não controlado, administraram cetamina IV em dez pacientes, com uma taxa de infusão de $0,3 \mathrm{mg} / \mathrm{kg}$ por hora, durante 100 minutos (equivalente a uma dose total de $0,5 \mathrm{mg} / \mathrm{kg})$. Cinco pacientes $(\mathrm{n}=10)$ alcançaram o estado de remissão. Não houveram aumentos significativos nas Escala de Avaliação Psiquiátrica (BPRS) ou na Escala de Mania de Young (YMRS). Dois pacientes que tiveram remissão $(n=5)$ demonstraram melhora ao longo do período de seguimento de quatro semanas (48).

De maneira a comparar o efeito antidepressivo rápido da cetamina com a terapia eletroconvulsiva (ECT), Ghasemi et al. (49), em 2014, administraram ambas técnicas em 18 pacientes hospitalizados com depressão maior. Foram utilizadas três infusões IV de cetamina $(0,5 \mathrm{mg} / \mathrm{kg}$, cada uma com duração de 45 minutos) ou três sessões de ECT em dias diferentes. Constataram que, após 24h, os sintomas depressivos melhoraram significativamente nos indivíduos que receberam a primeira dose de cetamina em comparação com a primeira sessão de ECT pelo grupo controle. Em comparação com os escores pré-tratamento, essa melhora permaneceu significativa ao longo do estudo. Assim como visto anteriormente, os sintomas depressivos após a segunda dose de cetamina obtiveram maior redução, em relação aos efeitos da segunda sessão de ECT. Ainda, estes efeitos antidepressivos do grupo cetamina foram atingidos mais rapidamente em comparação com o grupo controle (49).

Ballard et al. (50), um grupo de cientistas da região de Bethesda (EUA), analisaram a correlação entre o efeito da cetamina $(0,5 \mathrm{mg} / \mathrm{kg} \mathrm{IV}$, por 40 minutos $)$ sobre a ideação suicida, independentemente dos sintomas depressivos e/ou ansiosos dos pacientes. Neste estudo controlado, com placebo inativo, cruzado, randomizado e quádruplo-cego, realizado com 133 participantes, demonstrou-se que a infusão de cetamina esteve associada a reduções significativas na ideação suicida em comparação com o placebo, ao controlar os efeitos da cetamina na depressão $\left(\mathrm{F}_{1.587}=10,31, p=0,001\right)$ e ansiedade $\left(\mathrm{F}_{1.567}\right.$ $=8,54, p=.004)(50)$.

Em 2014, Lapidus et al. (51) demonstraram resultados de um ensaio performado no Centro Médico do Monte Sinai, com o intuito de testar a segurança, a tolerabilidade e a eficácia da cetamina intranasal em 20 pacientes com depressão, que haviam falhado em pelo menos um tratamento antidepressivo anterior. Realizou-se administrações intranasais (durante sete dias) de cloridrato de cetamina (50mg) e placebo inativo (solução salina), com pelo menos sete dias de intervalo após a última administração. Após $24 \mathrm{~h}$ da primeira administração intranasal de cetamina, os pacientes apresentaram melhora significativa nos sintomas depressivos em relação ao placebo $(t=4,39, p>0,001 ; 7,6 \pm$ 3,7; IC de 95\%, 3,9 - 11,3). Os critérios de resposta (redução $\geq 50 \%$ na escala MADRS) foram atingidos por oito pacientes $(44 \%, \mathrm{n}=20) 24$ horas após a administração da cetamina. Os mesmos critérios de resposta foram atingidos por um paciente $(6 \%, n=20)$ 
após a administração de placebo $(p=.033)$. A cetamina intranasal foi bem tolerada com efeitos psicotomiméticos ou dissociativos mínimos e não foi associada a alterações clinicamente significativas nos parâmetros hemodinâmicos, sendo estas algumas das vantagens da administração intranasal (51).

Murrough et al. (52), em 2015, avaliaram novamente os rápidos efeitos da cetamina intravenosa ( $0,5 \mathrm{mg} / \mathrm{kg}$, durante 40 minutos) em uma população com ideação suicida ( $\mathrm{n}=24)$, mas agora em âmbito ambulatorial ou hospitalar. Estabeleceram que o controle seria o agente anestésico midazolam $(0,45 \mathrm{mg} / \mathrm{kg}$, durante 40 minutos IV), como um controle psicoativo. O escore de ideação suicida, após 24h, foi significativamente menor nos indivíduos que receberam cetamina, em comparação com o grupo controle $(p=0,05)(52)$, validando os achados de 2011 dos pesquisadores de Yale - New Haven, Larkin et al. (46).

Vidal et al. (53), com o objetivo de documentar a segurança e testar os efeitos antidepressivos e antisuicidas de uma única injeção rápida $(0,5 \mathrm{mg} / \mathrm{kg}$ de cetamina $\mathrm{IV}$, durante um minuto) em dez pacientes com depressão resistente ao tratamento. Em relação à gravidade da depressão, expressa pela pontuação na escala MADRS, do período prétratamento de cetamina (média $=29$ [26 - 34]) aos 40 minutos após a primeira infusão (média $=14$ [10 - 29]), observou-se uma redução no escore. Um aumento nos escores ocorreu após quinze dias (média $=20$ [7 - 30], $P=0,029$ ). Oito pacientes atingiram os critérios de resposta (redução $\geq 50 \%$ na escala MADRS) no primeiro dia de tratamento, e após quatro semanas, todos estes voltaram ao estado não responsivo. A diminuição da ideação suicida (expressa pelas pontuações na escala SSI) apresentou melhora significativa no sétimo dia $(3,5[0$ - 26], $P=0,003)$, em comparação com os valores préinfusão de cetamina (12,5 [3 - 27]) (53).

No entanto, a fim de maximizar a redução de vieses, um estudo de Grunebaum et al. (54) buscou avaliar o efeito agudo da cetamina $(0,5 \mathrm{mg} / \mathrm{kg} \mathrm{IV}$, durante 40 minutos), utilizando o controle ativo $(0,02 \mathrm{mg} / \mathrm{kg}$ de midazolam IV, durante 40 minutos $)$, em 80 pacientes com ideação suicida de grande significância clínica. Assim como em estudos anteriores $(47,52)$, manteve-se o midazolam como placebo, pela sua similaridade de meiavida com a cetamina e pouco ou nenhum efeito antidepressivo. Houve uma notável redução dos sintomas de ideação suicida, após um dia de infusão de cetamina (diferença de 4,96 pontos), em comparação com o grupo que recebeu midazolam ( $95 \%$ CI $=2,33$ 7,59; Cohen's d = 0,75). Os efeitos colaterais foram de curta duração e a melhora clínica do paciente foi mantida por até seis semanas, em associação com uma farmacoterapêutica padronizada (54).

Em um ensaio controlado, paralelo, randomizado e duplo-cego, Phillips et al. (55), avaliaram os efeitos antidepressivos, em 41 participantes, de uma única infusão IV de cetamina, assim como de uma série de repetidas infusões e o prolongamento do efeito. Administraram $0,5 \mathrm{mg} / \mathrm{kg}$ IV de cloridrato de cetamina, por 40 minutos, e como controle, $30 \mu \mathrm{g} / \mathrm{kg}$ de midazolam, administrado por via IV. Após 24h da primeira infusão, o grupo que recebeu cetamina apresentou uma redução significativamente maior na pontuação da escala MADRS $(10,9 \pm 8,9)$, em comparação com o grupo controle $(2,8 \pm 3,6)$. Além disso, 23 participantes $(59 \%, \mathrm{n}=41)$ atenderam aos critérios de resposta (redução $\geq 50 \%$ na escala MADRS) após repetidas infusões (mediana de três infusões). No entanto, os participantes não tiveram nenhuma alteração significativa nos escores MADRS durante as infusões semanais de manutenção (55).

Zheng et al. (56) examinaram os efeitos sustentados de seis doses consecutivas de infusão de cetamina, em 77 pacientes chineses com transtorno de depressão maior. Foram administradas seis infusões IV de $0,5 \mathrm{mg} / \mathrm{kg}$ de cloridrato de cetamina, por 40 minutos. Este estudo intervencional, aberto e sem placebo, de 2019, demonstrou que após seis infusões de cetamina, $52(67,5 \%, \mathrm{n}=77)$ pacientes atingiram os critérios de resposta 
(redução $\geq 50 \%$ na escala MADRS) e $37(48,1 \%, n=77)$ obtiveram remissão. Ainda, houve uma redução média significativa na escala MADRS em quatro horas após a primeira infusão de cetamina $(7,0 \pm 7,5, p<0,001)$, e essa redução foi mantida durante o período de infusão (56).

A fim de contribuir com a literatura, Domany et al. (57) avaliaram a segurança, viabilidade, tolerabilidade e a eficácia de uma única e baixa dose de cetamina $(0,2 \mathrm{mg} / \mathrm{kg}$ IV, durante cinco minutos), ou placebo inativo, na redução da ideação suicida, em 18 pacientes deprimidos, de um pronto-socorro. O estudo teve um caráter de controle, paralelo, randomizado e duplo-cego. Observaram uma redução nos escores da Escala de Ideação Suicida de Beck (BSS) e MADRS-SI, no grupo que recebeu cetamina, após 90 180 minutos ( $p<0,05$ ), em comparação com o grupo placebo. Ainda, 90 minutos após a administração, $88 \%$ do grupo de cetamina havia atingido remissão da ideação suicida, em comparação com o grupo placebo $(33 \%, p<0,05)$. Não foram observados eventos adversos graves (57).

Embora o cenário da eficácia antidepressiva da cetamina se apresente significativamente positivo e esperançoso, destaca-se que os ensaios clínicos mencionados apresentam uma limitação quanto ao número de participantes dos estudos, com alguns deles contendo amostra menor que 30 indivíduos, o que pode limitar a análise e extrapolação dos resultados. Outro problema é a sua via de administração intravenosa que dificulta a autoadministração pelos próprios pacientes, além da possibilidade de ocorrência de eventos adversos das mais variáveis severidades, necessitando então, que o fármaco seja sempre utilizado em ambientes hospitalares. Logo, a fim de aumentar o alcance desta terapêutica, e com evidências sugerindo que o enantiômero escetamina tenha uma afinidade três vezes a quatro vezes maior para receptores N-metil-D-aspartato (NMDA) do que o enantiômero arcetamina (58-60), estudos avaliaram a administração intranasal de escetamina como uma estratégia para maior manutenção dos efeitos antidepressivos (61).

Os dados citados, advindos de estudos presentes na literatura abordando efeitos antidepressivos da cetamina em pacientes com depressão resistente ao tratamento ou transtorno depressivo maior, estão descritos na Tabela 1, em ordem da data de publicação.

Tabela 1 - Estudos presentes na literatura abordando efeitos antidepressivos da cetamina em pacientes com depressão resistente ao tratamento ou transtorno depressivo maior (continua).

\begin{tabular}{|c|c|c|c|c|}
\hline Estudos & Delineamento & $\mathbf{N}$ & Tratamento & Desfechos \\
\hline (25) & $\begin{array}{l}\text { Controlado, } \\
\text { cruzado, } \\
\text { randomizado, } \\
\text { duplo-cego. }\end{array}$ & 8 & $\begin{array}{l}0,5 \mathrm{mg} / \mathrm{kg} \text { IV de cloridrato de } \\
\text { cetamina, por } 40 \text { minutos ou } \\
\text { placebo inativo. }\end{array}$ & $\begin{array}{l}\text { - Houve melhora dos sintomas depressivos, dentro de } 72 \\
\text { horas após a infusão de cetamina; } \\
\text { - O grupo que recebeu infusão de placebo não obteve a } \\
\text { mesma melhora (HAMD: } 14 \pm 10 \text { pontos vs. } 0 \pm 12 \\
\text { pontos, respectivamente). }\end{array}$ \\
\hline (26) & $\begin{array}{l}\text { Controlado, } \\
\text { cruzado, } \\
\text { randomizado, } \\
\text { quádruplo-cego. }\end{array}$ & 18 & $\begin{array}{l}0,5 \mathrm{mg} / \mathrm{kg} \text { IV de cloridrato de } \\
\text { cetamina, por } 40 \text { minutos e } \\
\text { placebo inativo, com uma } \\
\text { semana de diferença. }\end{array}$ & $\begin{array}{l}\text { - Aos } 110 \text { minutos após a infusão, a cetamina apresentou } \\
\text { eficácia maior que o placebo }(\mathrm{d}=1,46 \text { [IC de } 95 \% \text {, } \\
0,91-2,01]) \text {; } \\
\text { - O efeito antidepressivo da cetamina permaneceu por } 7 \\
\text { dias }(\mathrm{d}=0,68 \text { [IC de } 95 \%, 0,13-1,23]) \text {. }\end{array}$ \\
\hline (42) & $\begin{array}{l}\text { Intervencional, } \\
\text { fatorial, } \\
\text { randomizado, } \\
\text { triplo-cego }\end{array}$ & 26 & $\begin{array}{l}\text { Cloridrato de cetamina }(0,5 \\
\mathrm{mg} / \mathrm{kg} \mathrm{IV} \text {, por } 40 \text { minutos })\end{array}$ & $\begin{array}{l}\text { Após } 24 \mathrm{~h} \text { de uma única infusão de cetamina, os } \\
\text { escores de comportamentos suicidas diminuíram } 2,08 \\
\text { pontos (MADRS-SI), em uma escala de } 0 \text { a } 6 \text { (valor } p \\
<0,001 \text { ). }\end{array}$ \\
\hline (43) & $\begin{array}{l}\text { Controlado, } \\
\text { fatorial, } \\
\text { randomizado, } \\
\text { triplo-cego }\end{array}$ & 26 & $\begin{array}{l}\text { Pré-tratamento com cetamina: } \\
\text { Placebo ou lamotrigina ( } 300 \mathrm{mg} \\
\text { VO); } \\
\text { Tratamento com cetamina: } \\
\text { Placebo inativo ou cetamina }(0,5 \\
\mathrm{mg} / \mathrm{kg} \mathrm{IV} \text {, por } 40 \text { minutos); } \\
\text { Pós-tratamento com cetamina: }\end{array}$ & $\begin{array}{l}65 \% \text { dos pacientes que receberam cetamina atenderam } \\
\text { aos critérios de resposta* em } 24 \text { horas. }\end{array}$ \\
\hline
\end{tabular}




\section{Kowalski et al. / Vittalle v. 33 n. 3 (2021) 134-154}

Riluzol (100 - 200 mg/d VO).

(44)

Intervencional,

aberto (sem

controle/placebo)
Intervencional,

aberto (sem controle/placebo)

ntervencional, aberto (sem controle/placebo)

ntervencional, aberto (sem

(49)

Controlado, cego e randomizado.

Controlado, cruzado, randomizado, duplo-cego.

Controlado, cruzado, randomizado, quádruplo-cego. controle/placebo)

$0,5 \mathrm{mg} / \mathrm{kg}$ IV de cloridrato de cetamina, por 40 minuto (múltiplas infusões durante 2 semanas).

Única infusão de $0,5 \mathrm{mg} / \mathrm{kg}$ IV de 33 cloridrato de cetamina, por 40 minutos.

Única infusão de $0,2 \mathrm{mg} / \mathrm{kg}$ IV de 14 cloridrato de cetamina, por 1-2 minutos, no departamento de emergência.

\section{Cetamina:}

Única infusão de $0,5 \mathrm{mg} / \mathrm{kg}$ IV de cloridrato de cetamina, por $40 \mathrm{~min}$.

\section{Controle:}

Única infusão de $0,45 \mathrm{mg} / \mathrm{kg}$ de midazolam, administrado por via IV, durante $40 \mathrm{~min}$.

Taxa de infusão de $0,3 \mathrm{mg} / \mathrm{kg}$ por 10 hora de cetamina IV, durante 100 minutos (equivalente a uma dose total de $0,5 \mathrm{mg} / \mathrm{kg}$ )

Cetamina:

Três infusões de $0,5 \mathrm{mg} / \mathrm{kg}$ de cloridrato de cetamina, por 45 minutos (em dias diferentes). Controle:

Três sessões de terapia eletroconvulsiva (em dias diferentes).
Administrações intranasais (durante sete dias) de cloridrato 20 de cetamina $(50 \mathrm{mg})$ e placebo inativo (solução salina), com pelo menos sete dias de intervalo após a última administração.
- Nove pacientes atingiram os critérios de resposta* após a primeira infusão (às $24 \mathrm{~h}, 6.9$ [2.8]), bem como após a sexta infusão (4h após a infusão, 5.0 [3,7]);

- Dos nove pacientes que receberam as múltiplas doses de cetamina, oito tiveram recaídas, em média, 30 dias após a primeira infusão e 19 dias após a sexta infusão (intervalo de seis dias a 45 dias);

- Um paciente permaneceu em remissão por mais de três meses após o tratamento com cetamina;

- A cetamina provocou sintomas psicóticos mínimos positivos e três pacientes experimentaram dissociação significativa, mas transitória;

- Os efeitos colaterais durante e após cada infusão de cetamina foram geralmente leves.

- Dez indivíduos apresentaram redução no escore (SSI $\geq$ 4 para SSI $\leq 4$ ) após a infusão de cetamina (nove desses após 40 minutos e um após 80 minutos);

- Sintomas de depressão, ansiedade e desesperança foram significativamente reduzidos em todos os pontos de tempo $(p<0,001)$

- Os escores médios do MADRS caíram significativamente de 40,4 $( \pm 1,8)$ pré-infusão de cetamina, para 11,5 $( \pm 2,2), 240$ minutos pós-infusão;

- Os índices de ideação suicida (MADRS-SI) também diminuíram significativamente, de 3,9 $( \pm 0,4)$ para 0,6 $( \pm 0,2)$, após 40 minutos da administração de cetamina

- Ainda, essa melhoria permaneceu por pelo menos 10 dias.

O grupo que recebeu cetamina apresentou maior redução na pontuação do MADRS, 24 horas após o tratamento, em comparação ao grupo controle, com uma diferença de 7,95 pontos (IC de 95\%, 3,20 a 12,71).

- Cinco pacientes alcançaram o estado de remissão;

- Não houveram aumentos significativos no BPRS ou YMRS;

- Dois desses pacientes que tiveram remissão demonstraram melhora ao longo do período de seguimento de quatro semanas.

- Após 24h, os sintomas depressivos melhoraram significativamente nos indivíduos que receberam a primeira dose de cetamina em comparação com o grupo controle;

- Em comparação com os escores pré-tratamento, essa melhora permaneceu significativa ao longo do estudo;

- Os sintomas depressivos após a segunda dose de cetamina obtiveram maior redução, em relação aos efeitos da segunda sessão de ECT;

- Ainda, estes efeitos antidepressivos do grupo cetamina foram atingidos mais rapidamente em comparação com o grupo controle.

Em comparação com o placebo, a cetamina esteve associada a reduções significativas da ideação suicida $\left(\mathrm{F}_{1.587}=10.31, p=0,001\right)$.

- Após $24 \mathrm{~h}$ da primeira administração intranasal de cetamina, os pacientes apresentaram melhora significativa nos sintomas depressivos em relação ao placebo $(t=4,39$, $p>0,001 ; 7,6 \pm 3,7 ;$ IC de $95 \%, 3,9-11,3$ );

- Os critérios de resposta* foram atingidos por oito pacientes (44\%), 24 horas após a administração da cetamina;

- Esses mesmos critérios de resposta* foram atingidos por um paciente $(6 \%)$, após a administração de placebo $(p=0,033)$

- A cetamina intranasal foi bem tolerada com efeitos psicotomiméticos ou dissociativos mínimos e não foi associada a alterações clinicamente significativas nos 
parâmetros hemodinâmicos.

Cetamina:

$0,5 \mathrm{mg} / \mathrm{kg}$ IV de cloridrato de cetamina, por $40 \mathrm{~min}$.
Controlado, paralelo, randomizado, quádruplo-cego
Intervencional e aberto
Uma única infusão IV de 10 cetamina $0,5 \mathrm{mg} / \mathrm{kg}$, por um minuto.
Controlado, paralelo, randomizado, quádruplo-cego
Intervencional e aberto
Controlado, paralelo, randomizado e duplo-cego.
Controlado, paralelo, randomizado e duplo-cego.
Seis infusões IV de $0,5 \mathrm{mg} / \mathrm{kg}$ de 77 cloridrato de cetamina, por 40 $\min$.

\section{Cetamina:}

$0,5 \mathrm{mg} / \mathrm{kg}$ IV de cloridrato de cetamina, por $40 \mathrm{~min}$

80 Controle:

$0,02 \mathrm{mg} / \mathrm{kg}$ de midazolam, administrado por via IV, durante $40 \mathrm{~min}$.

\section{Cetamina:}

$0,5 \mathrm{mg} / \mathrm{kg}$ IV de cloridrato de 41 cetamina, por $40 \mathrm{~min}$. Controle: $30 \mu \mathrm{g} / \mathrm{kg}$ de midazolam, administrado por via IV.

Infusão de placebo inativo ou 0,2 $18 \mathrm{mg} / \mathrm{kg}$ IV de cloridrato de cetamina, por cinco minutos, no departamento de emergência.
O escore de ideação suicida, após 24h, foi menor em pacientes que tiveram administração de cetamina, em comparação com o grupo controle $(p=0,05)$.
- Houve uma redução na pontuação da escala MADRS, do período pré-tratamento de cetamina (média=29 [26 - 34]) para os 40 minutos após a primeira infusão (média=14 [10 - 29]);

- Um aumento nos escores ocorreu após quinze dias (média=20 [7 - 30], $p=0,029$ );

- Oito pacientes atingiram os critérios de resposta* no primeiro dia de tratamento. Entretanto, após quatro semanas, todos estes voltaram ao estado não responsivo;

- A diminuição da ideação suicida (expressa pelas pontuações na escala SSI) apresentou melhora significativa no sétimo dia $(3,5[0-26], p=0,003)$, em comparação com os valores pré-infusão de cetamina $(12,5[3-27])$

O grupo que recebeu a cetamina, nas primeiras $24 \mathrm{~h}$, demonstrou uma maior redução na ideação suicida (diferença de 4,96 pontos), em comparação com o grupo que recebeu midazolam $(95 \% \mathrm{CI}=2.33,7.59$; Cohen's $\mathrm{d}^{* *}=0.75$ )

- Após $24 \mathrm{~h}$ da primeira infusão, o grupo que recebeu cetamina apresentou uma redução significativamente maior na pontuação da escala MADRS $(10,9[ \pm 8,9])$ em comparação com o grupo controle $(2,8[ \pm 3,6])$;

- 23 participantes $(59 \%, n=41)$ atenderam aos critérios de resposta após repetidas infusões (mediana de três infusões);

- No entanto, os participantes não tiveram nenhuma alteração significativa nos escores MADRS durante as infusões semanais de manutenção.

- Após seis infusões de cetamina, $52(67,5 \%)$ pacientes atingiram os critérios de resposta* e $37(48,1 \%)$ obtiveram remissão;

- Ainda, houve uma redução média significativa na escala MADRS, em quatro horas após a primeira infusão de cetamina $(7,0 \pm 7,5, p<0,001)$, e essa redução foi mantida durante o período de infusão.

- Observou-se uma redução da ideação suicida (escalas BSS e MADRS-SI), no grupo que recebeu cetamina, após 90 - 180 minutos $(p<0,05)$ da infusão de ativo, em comparação com o grupo placebo;

- Ainda, 90 minutos após a administração, $88 \%$ do grupo de cetamina havia atingido remissão da ideação suicida, em comparação com o grupo placebo $(33 \%, p$ $<0,05)$

- Não foram observados eventos adversos graves.

*(redução $\geq 50 \%$ na escala MADRS)

**Cohen's d está relacionado com o tamanho da diferença de efeito de cetamina-placebo.

Abreviaturas: IV: via intravenosa de administração; HAMD: Escala de Avaliação de Hamilton para Depressão; IC de 95\%: intervalo de confiança de 95\%; VO: via oral de administração; MADRS: Escala de Depressão de Montgomery e Asberg; TRD: depressão resistente ao tratamento; SSI: Escala para Ideação Suicida; MADRS-SI: Escala de Depressão de Montgomery e Asberg - Ideação Suicida; BPRS: Escala de Avaliação Psiquiátrica; YMRS: Escala de Mania de Young; ECT: terapia eletroconvulsiva; BSS: Escala de Ideação Suicida de Beck.

\section{Ensaios clínicos com a escetamina enquanto agente antidepressivo}

Em 2015, Singh et al. (61) apresentaram resultados do primeiro ensaio clínico abordando a escetamina enquanto um agente terapêutico no transtorno depressivo maior. 
Este estudo controlado, duplo-randomizado e duplo-cego, avaliou a eficácia e a segurança da administração intravenosa de escetamina em 30 pacientes com depressão resistente ao tratamento. O ensaio foi composto por duas etapas de intervenção. Na primeira, administrou-se escetamina $(0,2 \mathrm{mg} / \mathrm{kg}$ ou $0,4 \mathrm{mg} / \mathrm{kg} \mathrm{IV})$ ou placebo inativo (solução salina) durante 40 minutos. Na segunda, pacientes responsivos receberam o mesmo tratamento da primeira etapa, enquanto que pacientes que receberam placebo na primeira etapa, receberam infusão de escetamina $(0,2 \mathrm{mg} / \mathrm{kg}$ ou $0,4 \mathrm{mg} / \mathrm{kg} \mathrm{IV})$ e não responsivos, administrados com escetamina anteriormente, novamente receberam uma dose de ativo $(0,4 \mathrm{mg} / \mathrm{kg} \mathrm{IV})$, independentemente da dose anterior recebida. A média dos mínimos quadrados (MMQ) em relação aos escores MADRS, após 24h da primeira infusão de escetamina (primeira etapa), foi significativamente melhor no grupo que recebeu o ativo $(-16,8 \pm 3,0$ para $0,2 \mathrm{mg} / \mathrm{kg}$ e $-16,9 \pm 2,61$ para $0,4 \mathrm{mg} / \mathrm{kg})$ em comparação ao grupo placebo $(-3,8 \pm 2,97)$. A MMQ em relação aos escores MADRS, na segunda etapa, foi novamente significativamente melhor no grupo que recebeu o ativo $(-14,2 \pm 3,59$ para $0,2 \mathrm{mg} / \mathrm{kg}$ e $-13,2 \pm 3,16$ para $0,4 \mathrm{mg} / \mathrm{kg})$ em comparação ao grupo placebo $(-3,1 \pm 3,51)$. Ainda, a escetamina apresentou um rápido (duas horas) e robusto efeito antidepressivo. Os efeitos adversos mais comuns foram cefaleia, náusea e dissociação (que não persiste além de quatro horas do início da infusão). Entretanto, os pesquisadores ressaltaram a necessidade de novos estudos, a fim de avaliar a possibilidade da escetamina ser desenvolvida em forma farmacêutica diferente, de modo a evitar o inconveniente da infusão intravenosa, assim como uma maneira de obter resposta antidepressiva sustentada a longo prazo (61).

Com esses resultados e essa sugestão formulada por Singh et al. (61), um ensaio controlado, randomizado e duplo-cego, realizado em 14 locais (13 nos EUA e um na Bélgica), o estudo de Daly et al. (62), avaliou a eficácia, a segurança e a dose-resposta do cloridrato de escetamina intranasal em 126 pacientes com depressão resistente ao tratamento. Este estudo também contou com duas etapas de intervenção: no primeiro período (semana 1), os pacientes receberam placebo ou escetamina intranasal ( $28 \mathrm{mg}, 56$ mg ou $84 \mathrm{mg}$ ), duas vezes na semana; no segundo período (semana 2), o grupo placebo, com sintomas depressivos moderados (escore 11-16 no Inventário Rápido de Sintomatologia Depressiva [QIDS-SR 16 ]) ou severos (>16 na escala QIDS-SR 16 ), receberam a mesma intervenção do primeiro período. Pacientes sem sintomas ou com sintomas leves, continuaram a receber placebo inativo. Além destas duas etapas, houve a possibilidade de uma intervenção opcional, sendo uma infusão de $56 \mathrm{mg}$ de escetamina após 15 dias da primeira intervenção e $28-84 \mathrm{mg}$ nas doses subsequentes. A mudança na pontuação total na escala MADRS, em ambos os períodos, em todos os pacientes que receberam escetamina, foi superior ao grupo placebo (MMQ: escetamina $28 \mathrm{mg}:-4,2 \pm$ 2,09, $P=0,02$; $56 \mathrm{mg}:-6,3 \pm 2,07, P=0,001 ; 84 \mathrm{mg}:-9,0 \pm 2,13, P<0,001)$, doseresposta ascendente significativa $(P<0,001)$. Esta resposta antidepressiva se mostrou sustentada, com uma dose reduzida, por até nove semanas. Estes resultados impulsionaram uma investigação mais aprofundada da eficácia antidepressiva da escetamina intranasal (62).

Com o intuito de comparar a eficácia do tratamento antidepressivo padrão em associação com escetamina intranasal (84 mg ou placebo), Canuso et al. (63) verificaram, entre 68 indivíduos com risco iminente de suicídio, que após $4 \mathrm{~h}$ da primeira administração de escetamina, o grupo apresentou uma melhora no escore MADRS, em comparação com o grupo placebo (MMQ = 25,3 $\pm 2,10$; tamanho do efeito $=0,61$ ), assim como após 24 horas, $(\mathrm{MMQ}=27,2 \pm 2,85 ;$ tamanho do efeito $=0,65)$. Entretanto, não houveram alterações significativas no escore MADRS após 25 dias da administração (MMQ = 24,5 $\pm 3,14$; tamanho do efeito $=0,35$ ). Ainda, observaram melhora significativamente maior no grupo 
escetamina no escore MADRS-SI após quatro horas (tamanho do efeito $=0,67$ ), mas não em 24 horas (tamanho do efeito $=0,35)$ ou no dia 25 (tamanho do efeito $=0,29)(63)$.

Popova et al. (64), em 2019, compararam a segurança e eficácia da troca entre um antidepressivo (sem resposta terapêutica) para um spray nasal de escetamina, associado a um novo antidepressivo oral, em 223 pacientes adultos com depressão resistente ao tratamento. O placebo, ou escetamina intranasal (56 mg ou $84 \mathrm{mg}$ ), foi administrado duas vezes por semana, em associação com um novo antidepressivo oral, uma vez por dia (Escitalopram, Sertralina, Duloxetina ou Venlafaxina XR) por quatro semanas. A pontuação total de MADRS diminuiu significativamente nos primeiros 28 dias de tratamento com escetamina associada com antidepressivo $(21,4 \pm 12,32)$ em comparação ao grupo placebo associado a antidepressivo $(17,0 \pm 13,88)$. Entretanto, $7 \%$ da amostra interrompeu o uso de escetamina pelos efeitos adversos (dissociação, náusea, vertigem e disgeusia) (64).

Similarmente ao estudo de Popova et al. (64), Fedgchin et al. (65), compararam a segurança e eficácia de doses fixas do spray nasal de escetamina (56 mg ou $84 \mathrm{mg}$ ), ou placebo, associado a um antidepressivo oral, em 346 pacientes com depressão resistente ao tratamento. Assim como o estudo anterior (64), a pontuação total de MADRS diminuiu significativamente nos primeiros 28 dias de tratamento com antidepressivos orais associados a escetamina $56 \mathrm{mg}(19,0 \pm 13,86)$ e escetamina $84 \mathrm{mg}(18,8 \pm 14,12) \mathrm{em}$ comparação ao grupo placebo associado a antidepressivo $(14,8 \pm 15,07)$. Os efeitos adversos mais comuns reportados pelo grupo escetamina foi náusea, dissociação, tontura, vertigem e cefaleia (65).

Daly et al. (66), a partir de um estudo controlado, paralelo, randomizado e duplo-cego, avaliaram a eficácia da escetamina intranasal (56 $\mathrm{mg}$ ou $84 \mathrm{mg}$ ), ou placebo em associação a um antidepressivo oral, no retardo da recidivados sintomas depressivos, em 297 pacientes com depressão resistente ao tratamento em remissão estável (após tratamento com escetamina intranasal associada a um antidepressivo oral). Entre todos os participantes, 176 deles alcançaram uma remissão estável. Destes, em relação a recidivados sintomas depressivos, no grupo placebo houveram 45,3\% $(\mathrm{n}=39)$, enquanto no grupo da escetamina 26,7\% $(n=24)$. Ainda, 121 pacientes $(n=297)$ obtiveram uma resposta antidepressiva estável. Destes, em relação a recidiva, no grupo placebo houveram 57,6\% ( $n=34)$, enquanto que no grupo da escetamina 25,8\% ( $n=16)$. Particularmente, a administração de escetamina associada com antidepressivo oral, resultou em superioridade clinicamente significativa no retardo da recidiva em comparação com antidepressivo associado ao placebo (66).

Em 2020, pesquisadores brasileiros (67) conduziram o primeiro ensaio de comparação direta, avaliando a segurança e eficácia da escetamina em comparação com a cetamina, em 63 pacientes com depressão resistente ao tratamento. Correia-Melo et al. (67), administraram escetamina $(0,25 \mathrm{mg} / \mathrm{kg} \mathrm{IV}$, durante 40 minutos) ou cetamina $(0,5 \mathrm{mg} / \mathrm{kg}$ IV, durante 40 minutos). Após 24 horas, sete participantes $(24,1 \%, \mathrm{n}=29)$ que receberam infusão de cetamina, e dez $(29,4 \%, n=34)$ que receberam escetamina, apresentaram remissão, com uma diferença de 5,3\% (Intervalo de confiança do Limite Inferior [ $\mathrm{IC}_{\mathrm{BL}}$ ] de $95 \%,-13,6 \%$ ), confirmando a não inferioridade entre ambas. Os escores na escala MADRS tiveram reduções significativas, tanto no grupo cetamina (33 $\pm 9,3$ para $16,2 \pm$ $10,7)$ como no grupo escetamina $(33 \pm 5,3$ para $17,5 \pm 12,2)$, com diferença de $-5,27 \%$ (IC BL de 95\%, -13,6\%) (67).

Wajs et al. (68), a partir de um ensaio intervencional, aberto e de longo prazo, avaliaram a segurança e eficácia, em longo prazo, do spray nasal de escetamina ( $28 \mathrm{mg}, 56 \mathrm{mg}$ ou $84 \mathrm{mg}$ ), ou placebo, associado a um antidepressivo oral (Escitalopram, Sertralina, Duloxetina ou Venlafaxina XR), em 802 pacientes com depressão resistente ao 
tratamento. A pontuação total de MADRS diminuiu durante a fase inicial de tratamento, e esta redução persistiu durante a fase de otimização e manutenção $(16,4 \pm 8,76$ e 0,3 \pm 8,12 , respectivamente). Ainda, 76 pacientes (9,5\% da amostra) interromperam o uso de escetamina pelos efeitos adversos (tontura, dissociação, náusea e cefaleia), e 55 pacientes $(6,9 \%)$ experenciaram sérios efeitos adversos (ideação suicida, tentativa de suicídio, ansiedade e delírio) (68).

Dong-Jing Fu et al. (69) avaliaram a eficácia da escetamina em comparação com o placebo intranasal, associado a um antidepressivo padrão, a fim de reduzir sintomas do transtorno depressivo maior, incluindo ideação suicida. Os 226 pacientes foram randomizados, de modo duplo-cego, a receber placebo ou escetamina intranasal $(84 \mathrm{mg}$ ou 56mg), em associação com antidepressivo oral (a escolha do fármaco padronizado pelos protocolos foi realizada por um investigador clínico), e se necessário, realizaram uma associação a um terceiro fármaco (antidepressivo, antipsicótico atípico ou estabilizador de humor). Houveram reduções significativas nas pontuações de MADRS no grupo do ativo escetamina em comparação com o grupo placebo, em 24 horas (diferença da MMQ: $-3,8[ \pm 1,39]$; IC de 95\%, -6,56 a -1,09; $P$ bilateral $=0,006$ ). A diferença na gravidade do suicídio não foi estatisticamente significativa entre os grupos (mediana da diferença [IC 95\%]: 0,0 [-1,00 a 0,00]; $P$ bilateral $=0,107$ ). Os eventos adversos mais comuns entre os pacientes tratados com escetamina foram tontura, dissociação, dor de cabeça, náusea e sonolência (69).

O mais recente estudo presente na literatura, realizado por Ionescu et al. (70), com metodologia similar à de Dong-Jing Fu et al. (69), também objetivou avaliar a eficácia da escetamina intranasal ( $84 \mathrm{mg}$ ou $56 \mathrm{mg}$ ), em comparação com o placebo intranasal, associado a um antidepressivo padrão, a fim de reduzir sintomas do transtorno depressivo maior, tal como a ideação suicida. Se houvesse necessidade, uma associação a um terceiro fármaco (antidepressivo, antipsicótico atípico ou estabilizador de humor) poderia ser realizada. Houveram reduções significativas nas pontuações de MADRS no grupo do ativo escetamina em comparação com o grupo placebo, em 24 horas (diferença da MMQ: $-3,9 \pm 1,39 ;$ IC de $95 \%,-6,60$ a $-1,11 ; P$ bilateral $=0,006)$. A diferença na gravidade do suicídio não foi estatisticamente significativa entre os grupos, apesar da rápida redução nas pontuações da Escala de Impressão Clínica Global - Gravidade do Suicídio (CGI-SS). Os eventos adversos mais comuns entre os pacientes tratados com escetamina foram tontura, dissociação, náusea, disgeusia, sonolência, cefaleia e parestesia (70).

Os dados citados, advindos de estudos presentes na literatura abordando efeitos antidepressivos da escetamina em pacientes com depressão resistente ao tratamento ou transtorno depressivo maior, estão descritos na Tabela 2, em ordem da data de publicação.

Tabela 2 - Estudos presentes na literatura abordando efeitos antidepressivos da escetamina em pacientes com depressão resistente ao tratamento ou transtorno depressivo maior (continua).

\begin{tabular}{|c|c|c|c|c|}
\hline Estudos & Delineamento & $\mathbf{N}$ & Tratamento & Desfechos \\
\hline (61) & $\begin{array}{l}\text { Controlado, } \\
\text { duplo- } \\
\text { randomizado } \\
\text { e duplo-cego. }\end{array}$ & 30 & $\begin{array}{l}\text { Primeira etapa: } \\
\text { infusão IV de } 0,2 \mathrm{mg} / \mathrm{kg} \text { ou } 0.4 \mathrm{mg} / \mathrm{kg} \\
\text { de escetamina ou placebo inativo } \\
\text { (solução salina) durante } 40 \text { minutos. } \\
\text { Segunda etapa: } \\
\text { Pacientes responsivos receberam o } \\
\text { mesmo tratamento da primeira etapa; } \\
\text { pacientes não responsivos, que } \\
\text { receberam placebo na primeira etapa, } \\
\text { receberam nova infusão de } \\
\text { escetamina IV } 0.2 \mathrm{mg} / \mathrm{kg} \text { ou } 0.4 \\
\text { mg/kg e não responsivos que } \\
\text { receberam escetamina, receberam } \\
0,4 \mathrm{mg} / \mathrm{kg} \text {, independentemente da }\end{array}$ & $\begin{array}{l}\text { - A MMQ dos escores MADRS, após 24h da } \\
\text { primeira infusão de escetamina (primeira etapa), foi } \\
\text { significativamente melhor no grupo que recebeu o } \\
\text { ativo (-16,8 } \pm 3,0 \text { para } 0,2 \mathrm{mg} / \mathrm{kg} \text { e }-16,9 \pm 2,61 \text { para } \\
0,4 \mathrm{mg} / \mathrm{kg} \text { ) em comparação ao grupo placebo (-3,8 } \pm \\
2,97) \text {; } \\
\text { - Na segunda etapa, a MMQ dos escores MADRS, } \\
\text { foi novamente significativamente melhor no grupo } \\
\text { que recebeu o ativo }(-14,2 \pm 3,59 \text { para } 0,2 \mathrm{mg} / \mathrm{kg} \text { e - } \\
13,2 \pm 3,16 \text { para } 0,4 \mathrm{mg} / \mathrm{kg} \text { ) em comparação ao } \\
\text { grupo placebo (-3, } \pm 3,51) ; \\
\text { - Escetamina apresentou um rápido (duas horas) e } \\
\text { robusto efeito antidepressivo; } \\
\text { - Os efeitos adversos mais comuns foram cefaleia, }\end{array}$ \\
\hline
\end{tabular}


Controlado, randomizado, duplo-cego.
Controlado,

(63) randomizado e duplo-cego.
Controlado,

(64) randomizado e duplo-cego.

Controlado, andomizado e duplo-cego.
Controlado, paralelo, randomizado e duplo-cego.
Controlado, paralelo, randomizado e duplo-cego.
Primeiro período (semana 1): Placebo ou escetamina intranasal (28 $\mathrm{mg}, 56 \mathrm{mg}$ ou $84 \mathrm{mg}$ ), duas vezes na semana.

Segundo período (semana 2): A mudança na pontuação total na escala MADRS, em Grupo placebo, com sintomas ambos os períodos, em todos os pacientes que depressivos moderados (escore 11-16 receberam escetamina, foi superior ao grupo placebo. na escala QIDS-SR ${ }_{16}$ ) ou severos Expressa-se pela MMQ:

126 (>16 na escala QIDS-SR 16$)$, receberam mesma intervenção do primeiro período. Pacientes sem sintomas ou com sintomas leves, continuaram a receber placebo. Intervenção opcional: $56 \mathrm{mg}$ de escetamina após 15 dias da primeira intervenção e $28-84 \mathrm{mg}$ nas doses subsequentes.

Associação entre antidepressivo padronizado pelos protocolos clínicos e 84mg de escetamina intranasal ou placebo inativo.

Escetamina intranasal $(56 \mathrm{mg}$ ou 84mg) (ou placebo) 2x/semana em associação com antidepressivo 1x/dia ([Escitalopram ou Sertralina] ou [Duloxetina ou Venlafaxina XR]) por quatro semanas.

Escetamina intranasal $(56 \mathrm{mg}$ ou $84 \mathrm{mg}$ ) (ou placebo) 2x/semana em associação com antidepressivo 1x/dia ([Escitalopram ou Sertralina] ou [Duloxetina ou Venlafaxina XR]) por quatro semanas.

Escetamina intranasal $(56 \mathrm{mg}$ ou $84 \mathrm{mg}$ ) (ou placebo) em associação com antidepressivo ([Escitalopram ou Sertralina] ou [Duloxetina ou Venlafaxina $\mathrm{XR}]$ ) por quatro semanas.

\section{Escetamina}

$0,25 \mathrm{mg} / \mathrm{kg}$ de escetamina, administrada por via IV, durante 40 minutos.

Cetamina:

$0,5 \mathrm{mg} / \mathrm{kg}$ de cloridrato de cetamina, administrada por via IV, por 40
- $28 \mathrm{mg}:-4,2 \pm 2,09, P=0,02$;

- $56 \mathrm{mg}:-6,3 \pm 2,07, P=0,001$;

- $84 \mathrm{mg}:-9,0 \pm 2,13, P<0,001)$.

Dose-resposta ascendente significativa $(\mathrm{P}<0,001)$.
Após 4h da primeira administração de escetamina, o grupo apresentou uma melhora no escore MADRS, em comparação com o grupo placebo $(\mathrm{MMQ}=25,3 \pm 2,10$; tamanho do efeito $=0,61$ ), assim como após 24 horas, (MMQ $=27,2 \pm 2,85 ;$ tamanho do efeito $=0,65$ );

- Entretanto, não houveram alterações significativas no escore MADRS após 25 dias da administração $(\mathrm{MMQ}=24,5 \pm 3,14]$; tamanho do efeito $=0,35)$;

- Ainda, observou-se melhora significativamente maior no grupo escetamina no escore MADRS-SI após 4 horas (tamanho do efeito $=0,67$ ), mas não em 24 horas (tamanho do efeito $=0,35$ ) ou no dia 25 (tamanho do efeito $=0,29)$.

- A pontuação total de MADRS diminuiu significativamente nos primeiros 28 dias de tratamento com escetamina associada ao antidepressivo $(21,4 \pm 12,32)$ em comparação ao grupo placebo associado a antidepressivo (17,0 \pm 13,88);

- Entretanto, $7 \%$ da amostra controle interrompeu o uso de escetamina pelos efeitos adversos (dissociação, náusea vertigem e disgeusia).

- A pontuação total de MADRS diminuiu significativamente nos primeiros 28 dias de tratamento com antidepressivos orais associados a escetamina $56 \mathrm{mg}(19,0 \pm 13,86)$ e escetamina $84 \mathrm{mg}(18,8 \pm 14,12)$ em comparação ao grupo placebo associado a antidepressivo $(14,8 \pm 15,07)$;

- Os efeitos adversos mais comuns reportados pelo grupo escetamina foram: náusea, dissociação, tontura, vertigem e cefaleia.

- 176 pacientes alcançaram uma remissão estável;

- 39 pacientes desses, pertencentes ao grupo placebo, apresentaram recaídas dos sintomas depressivos, assim como 24 pacientes do grupo da escetamina;

- 121 pacientes $(n=297)$ obtiveram uma resposta estável;

- 34 pacientes desses, pertencentes ao grupo placebo, apresentaram recaídas dos sintomas depressivos, assim como 16 pacientes do grupo da escetamina.

- Após 24 horas, sete participantes $(24,1 \%, n=29)$ que receberam infusão de cetamina, e dez $(29,4 \%, n=34)$ que receberam escetamina, apresentaram remissão, com uma diferença de $5,3 \%$ ( $\mathrm{IC}_{\mathrm{BL}}$ de $95 \%,-13,6 \%$ ), confirmando a não inferioridade entre ambas;

- Os escores na escala MADRS tiveram reduções significativas, tanto no grupo cetamina (33 $\pm 9,3$ para $16,2 \pm 10,7)$ como no grupo escetamina $(33 \pm$ 
minutos.

Escetamina intranasal $(28 \mathrm{mg}, 56 \mathrm{mg}$ ou $84 \mathrm{mg}$ ) (ou placebo) $2 \mathrm{x} / \mathrm{semana}$ em associação com antidepressivo $1 \mathrm{x} /$ dia (ISRS [Escitalopram ou Sertralina] ou [Duloxetina ou Venlafaxina XR]).

Placebo ou escetamina intranasal ( $84 \mathrm{mg}$ ou $56 \mathrm{mg}$ ), em associação com antidepressivo oral (escolha do fármaco padronizado pelos protocolos foi realizada por um investigador clínico), e se necessário, associação a um terceiro fármaco (antidepressivo, antipsicótico atípico ou estabilizador de humor).

Placebo ou escetamina intranasa (84mg ou 56mg), em associação com antidepressivo oral (escolha do fármaco padronizado pelos protocolos foi realizada por um investigador clínico), e se necessário, associação a um terceiro fármaco (antidepressivo, antipsicótico atípico ou estabilizador de humor).
5,3 para $17,5 \pm 12,2$ ), com diferença de $-5,27 \%$ $\left(\mathrm{IC}_{\mathrm{BL}}\right.$ de $\left.95 \%,-13,6 \%\right)$.

- A pontuação total de MADRS diminuiu durante a fase inicial de tratamento, e esta redução persistiu durante a fase de otimização e manutenção (16,4 \pm 8,76 e $0,3 \pm 8,12$, respectivamente);

- Ainda, 9,5\% da amostra interrompeu o uso de escetamina pelos efeitos adversos (tontura, dissociação, náusea e cefaleia);

- 55 pacientes $(6,9 \%)$ experenciaram sérios efeitos adversos.

- Houveram reduções significativas nas pontuações de MADRS no grupo do ativo escetamina em comparação com o grupo placebo, em 24 horas (MMQ: $-3,8 \pm 1,39$; IC de 95\%, -6,56 a -1,09; $P$ bilateral $=0,006$ );

- A diferença na gravidade do suicídio não foi estatisticamente significativa entre os grupos (mediana da diferença [IC 95\%]: 0,0 [-1,00 a $0,00]$; $P$ bilateral $=0,107)$;

- Os eventos adversos mais comuns entre os pacientes tratados com escetamina foram tontura, dissociação, dor de cabeça, náusea e sonolência.

- Houveram reduções significativas nas pontuações de MADRS no grupo do ativo escetamina em comparação com o grupo placebo, em 24 horas (MMQ: $-3,9 \pm 1,39 ;$ IC de $95 \%,-6,60$ a $-1,11 ; P$ bilateral $=0,006$ );

- A diferença na gravidade do suicídio não foi estatisticamente significativa entre os grupos, apesar da rápida redução nas pontuações da CGI$\mathrm{SS}$;

- Os eventos adversos mais comuns entre os pacientes tratados com escetamina foram tontura, dissociação, náusea, disgeusia, sonolência, cefaleia e parestesia.

Abreviaturas: IV: via intravenosa de administração; MMQ: Média dos Quadrados Mínimos; MADRS: Escala de Depressão de Montgomery e Asberg; QIDS-SR 16 : Inventário Rápido de Sintomatologia Depressiva; MADRS-SI: Escala de Depressão de Montgomery e Asberg - Ideação Suicida; IC $C_{B L}$ : Limite Inferior do Intervalo de Confiança de 95\%; CGI-SS: Escala de Impressão Clínica Global - Gravidade do Suicídio.

\section{Considerações Finais}

Com o presente estudo, tornou-se possível revisar estudos clínicos envolvendo a cetamina, e seu enantiômero escetamina, no tratamento do transtorno de depressão maior e/ou depressão resistente ao tratamento. Foram observadas comprovações científicas sobre a segurança, tolerabilidade e eficácia terapêutica de variadas doses, vias de administração, tempo ou taxa de infusão do fármaco, assim como o tamanho da população de estudo. O compartilhamento de tais resultados na literatura possibilita aos pesquisadores, o desenvolvimento, ou elucidação, de metodologias que possam, cada vez mais, agregar com a solução do problema em questão: o estabelecimento de um antagonista de NMDA enquanto agente antidepressivo.

Entretanto, cetamina e escetamina mantém-se como medicamentos, apesar de promissores, de alto risco, pela grande capacidade observada de gerar efeitos adversos de severidades variadas, incluindo dissociação, sonolência, parestesia, tontura, vertigem, ansiedade, delírio e tendência suicida. Estas características põem em vista a necessidade de se atentar à melhor via de administração para cada caso em particular, com a via intravenosa para pacientes com ideação suicida (pelos rápidos efeitos antidepressivos) e intranasal em casos de depressão moderada. Logo, torna-se imprescindível que sejam realizadas novas análises em relação à segurança e tolerabilidade de ambos fármacos, para que seja possível, em um futuro momento, a autoadministração segura e eficaz de cetamina ou seu enantiômero. Ademais, ambos fármacos ainda se apresentam demasiadamente caros no mercado comercial, 
aumentando a dificuldade do acesso pelos pacientes.

\section{Referências}

1. Organização Pan-Americana da Saúde. Depressão [Internet]. Organização Mundial da Saúde. 2021. Disponível em: https://www.paho.org/pt/topicos/depressao

2. Abelha L. Depressão, uma questão de saúde pública. Cad Saúde Coletiva. 2014; 22 (3):223-223.

3. American Psychiatric Association. Diagnostic and Statistical Manual of Mental Disorders - DSM-5 [Internet]. 5th ed. Vol. 5. Porto Alegre: American Psychiatric Association; 2014. 948 p. [Citado em 2021 Jun 21]. Disponível em: https://periodicos.ufsc.br/index.php/interthesis/article/view/1807$1384.2014 \mathrm{v} 11 \mathrm{n} 2 \mathrm{p} 96$

4. World Health Organization. Depression and Other Common Mental Disorders - Global Health Estimates. Vol. 1. Geneva; 2017. 24 p.

5. Quevedo J, Izquierdo I. Neurobiologia dos transtornos psiquiátricos. 1st ed. Porto Alegre: Artmed; 2020. $538 \mathrm{p}$.

6. Sullivan PF, Neale MC, Kendler KS. Genetic epidemiology of major depression: Review and metaanalysis. Am J Psychiatry. 2000; 157(10): 1552-62.

7. Sanacora G, Treccani G, Popoli M. Towards a glutamate hypothesis of depression: An emerging frontier of neuropsychopharmacology for mood disorders. Neuropharmacology. 2012; 62(1):63-77.

8. Bunney WE, Bunney BG. Molecular clock genes in man and lower animals: Possible implications for circadian abnormalities in depression. Neuropsychopharmacology. 2000; 22(4): 335-45.

9. Belmaker RH, Agam G. Major Depressive Disorder. N Engl J Med. 2008; 358(1): 55-68.

10. Sanacora G, Saricicek A. GABAergic Contributions to the Pathophysiology of Depression and the Mechanism of Antidepressant Action. CNS Neurol Disord - Drug Targets. 2008; 6(2): 127-40.

11. Anderson R, Freedland K, RE C, Lustman PJ. The Prevalence of Comorbid Depression. Diabetes Care. 2001; 24(6): 1069-78.

12. Cosci F, Chouinard G. The monoamine hypothesis of depression revisited: Could it mechanistically novel antidepressant strategies? Neurobiol Depress Road to Nov Ther 2019; 63-73.

13. Trullas R, Skolnick P. Functional antagonists at the NMDA receptor complex exhibit antidepressant actions. Eur J Pharmacol. 1990; 185(1):1-10.

14. Duman RS, Li N. A neurotrophic hypothesis of depression: role of synaptogenesis in the actions of NMDA receptor antagonists. Philos Trans R Soc B Biol Sci. 2012; 367(1601): 2475-84.

15. Fekadu N, Shibeshi W, Engidawork E. Major Depressive Disorder: Pathophysiology and Clinical Management. J Depress Anxiety. 2017; 6:1.

16. Al-harbi. Treatment-resistant depression: therapeutic trends, challenges, and future directions. Patient Prefer Adherence. 2012; 6: 369-88.

17. Ionescu DF, Felicione JM, Gosai A, Cusin C, Shin P, Shapero BG, et al. Ketamine-Associated Brain Changes. Harv Rev Psychiatry. 2018; 26(6): 320-339.

18. Ramaker MJ, Dulawa SC. Identifying fast-onset antidepressants using rodent models. Mol Psychiatry. 2017; 22(5): 656-65.

19. Katzung BG, Trevor AJ. Farmacologia básica e clínica. 13th ed. [tradução: Ademar Valadares Fonseca et al. ; revisão técnica: Almir Lourenço da Fonseca]., editor. AMGH. Porto Alegre: AMGH; 2017. 1216 p.

20. Hyman SE. Psychiatric Drug Development: Diagnosing a Crisis. Cerebrum. 2013; 2013:5.

21. Phillips AG, Hongaard-Andersen P, Moscicki RA, Sahakian B, Quirion R, Krishnan KRR, et al. Proceedings of the 2013 CINP Summit: Innovative Partnerships to Accelerate CNS Drug Discovery for Improved Patient Care. Int J Neuropsychopharmacol. 2015; 18(3): pyu100-pyu 100.

22. Iadarola ND, Niciu MJ, Richards EM, Vande Voort JL, Ballard ED, Lundin NB, et al. Ketamine and other N-methyl-D-aspartate receptor antagonists in the treatment of depression: a perspective review. Ther Adv Chronic Dis. 2015; 6(3): 97-114.

23. National Center for Biotechnology Information. PubChem Compound Summary for CID 3821, Ketamine [Internet]. 2020. Disponível em: https://pubchem.ncbi.nlm.nih.gov/compound/3821

24. Sinner B, Graf BM. Ketamine. In: Modern Anesthetics. Berlin, Heidelberg: Springer Berlin Heidelberg; p. 313-33.

25. Berman RM, Cappiello A, Anand A, Oren DA, Heninger GR, Charney DS, et al. Antidepressant effects of ketamine in depressed patients. Biol Psychiatry. 2000; 47(4): 351-4.

26. Zarate CAJ, Singh JB, Carlson PJ, Brutsche NE, Ameli R, Luckenbaugh DA, et al. A Randomized Trial of an N-methyl-D-aspartate Antagonist in Treatment-Resistant Major Depression. Arch Gen Psychiatry. 2006; 63(8): 856-64.

27. Paul IA, Skolnick P. Glutamate and Depression. Ann N Y Acad Sci. 2003; 1003(1): 250-72.

28. McKinney RA, Capogna M, Dürr R, Gähwiler BH, Thompson and SM. Miniature synaptic events 
maintain dendritic spines via AMPA receptor activation. Nat Neurosci. 1999; 2(1): 44-9.

29. Hashimoto K, Sawa A, Iyo M. Increased Levels of Glutamate in Brains from Patients with Mood Disorders. Biol Psychiatry. 2007; 62(11): 1310-6.

30. Homayoun H, Moghaddam B. NMDA Receptor Hypofunction Produces Opposite Effects on Prefrontal Cortex Interneurons and Pyramidal Neurons. J Neurosci. 2007; 27(43): 11496-500.

31. Zanos P, Gould TD. Mechanisms of ketamine action as an antidepressant. Mol Psychiatry. 2018; 23(4): 801-11.

32. Abdallah CG, Adams TG, Kelmendi B, Esterlis I, Sanacora G, Krystal JH. Ketamine's mechanism of action: a path to rapid-acting antidepressants. Depress Anxiety. 2016; 33(8):689-97.

33. Autry AE, Adachi M, Nosyreva E, Na ES, Los MF, Cheng P, et al. NMDA receptor blockade at rest triggers rapid behavioural antidepressant responses. Nature. 2011; 475(7354): 91-5.

34. Mathew SJ, Shah A, Lapidus K, Clark C, Jarun N, Ostermeyer B, et al. Ketamine for TreatmentResistant Unipolar Depression. CNS Drugs. 2012; 26(3): 189-204.

35. Jourdi H, Hsu Y-T, Zhou M, Qin Q, Bi X, Baudry M. Positive AMPA Receptor Modulation Rapidly Stimulates BDNF Release and Increases Dendritic mRNA Translation. J Neurosci. 2009; 29(27): 8688-97.

36. Lepack AE, Fuchikami M, Dwyer JM, Banasr M, Duman RS. BDNF Release Is Required for the Behavioral Actions of Ketamine. Int J Neuropsychopharmacol. 2015; 18(1): pyu033-pyu033.

37. Li N, Lee B, Liu R-J, Banasr M, Dwyer JM, Iwata M, et al. mTOR-Dependent Synapse Formation Underlies the Rapid Antidepressant Effects of NMDA Antagonists. Science. 2010; 329(5994): 959-64.

38. Abdallah CG, Averill LA, Gueorguieva R, Goktas S, Purohit P, Ranganathan M, et al. Modulation of the antidepressant effects of ketamine by the mTORC1 inhibitor rapamycin. Neuropsychopharmacology. 2020; 45(6):990-7.

39. Abdallah CG, Averill LA, Collins KA, Geha P, Schwartz J, Averill C, et al. Ketamine Treatment and Global Brain Connectivity in Major Depression. Neuropsychopharmacology. 2017; 42(6): 1210-9.

40. Souza MT de, Silva MD da, Carvalho R de. Revisão integrativa: o que é e como fazer. Einstein. 2010; 8(1): 102-6.

41. Mendes KDS, Silveira RC de CP, Galvão CM. Revisão Integrativa: método de pesquisa para a incorporação de evidências na saúde e na enfermagem. Texto Context Enferm. 2008; 17(4): 758-64.

42. Price RB, Nock MK, Charney DS, Mathew SJ. Effects of Intravenous Ketamine on Explicit and Implicit Measures of Suicidality in Treatment-Resistant Depression. Biol Psychiatry. 2009; 66(5):522-6.

43. Mathew SJ, Murrough JW, aan het Rot M, Collins KA, Reich DL, Charney DS. Riluzole for relapse prevention following intravenous ketamine in treatment-resistant depression: a pilot randomized, placebo-controlled continuation trial. Int J Neuropsychopharmacol. 2010; 13(1): 71-82.

44. aan het Rot M, Collins KA, Murrough JW, Perez AM, Reich DL, Charney DS, et al. Safety and Efficacy of Repeated-Dose Intravenous Ketamine for Treatment-Resistant Depression. Biol Psychiatry. 2010; 67(2): 139-45.

45. DiazGranados N, Ibrahim LA, Brutsche NE, Ameli R, Henter ID, Luckenbaugh DA, et al. Rapid Resolution of Suicidal Ideation After a Single Infusion of an N -Methyl- D -Aspartate Antagonist in Patients With Treatment-Resistant Major Depressive Disorder. J Clin Psychiatry. 2010; 71(12): 1605-11.

46. Larkin GL, Beautrais AL. A preliminary naturalistic study of low-dose ketamine for depression and suicide ideation in the emergency department. Int J Neuropsychopharmacol. 2011; 14(8):1127-31.

47. Murrough JW, Iosifescu D V, Chang LC, Al Jurdi RK, Green CE, Perez AM, et al. Antidepressant Efficacy of Ketamine in Treatment-Resistant Major Depression: A Two-Site Randomized Controlled Trial. Am J Psychiatry. 2013; 170(10): 1134-42.

48. Rasmussen KG, Lineberry TW, Galardy CW, Kung S, Lapid MI, Palmer BA, et al. Serial infusions of low-dose ketamine for major depression. J Psychopharmacol. 2013; 27(5): 444-50.

49. Ghasemi M, Kazemi MH, Yoosefi A, Ghasemi A, Paragomi P, Amini H, et al. Rapid antidepressant effects of repeated doses of ketamine compared with electroconvulsive therapy in hospitalized patients with major depressive disorder. Psychiatry Res. 2014; 215(2): 355-61.

50. Ballard ED, Ionescu DF, Vande Voort JL, Niciu MJ, Richards EM, Luckenbaugh DA, et al. Improvement in suicidal ideation after ketamine infusion: Relationship to reductions in depression and anxiety. J Psychiatr Res. 2014; 58:161-6.

51. Lapidus KAB, Levitch CF, Perez AM, Brallier JW, Parides MK, Soleimani L, et al. A Randomized Controlled Trial of Intranasal Ketamine in Major Depressive Disorder. Biol Psychiatry. 2014; 76(12):970-6.

52. Murrough JW, Soleimani L, Dewilde KE, Collins KA, Lapidus KA, Iacoviello BM, et al. Ketamine for rapid reduction of suicidal ideation: A randomized controlled trial. Psychol Med. 2015; 45(16): 3571-80.

53. Vidal S, Gex-Fabry M, Bancila V, Michalopoulos G, Warrot D, Jermann F, et al. Efficacy and Safety 
of a Rapid Intravenous Injection of Ketamine $0.5 \mathrm{mg} / \mathrm{kg}$ in Treatment-Resistant Major Depression. J Clin Psychopharmacol. 2018; 38(6): 590-7.

54. Grunebaum MF, Galfalvy HC, Choo T-HH, Keilp JG, Moitra VK, Parris MS, et al. Ketamine for rapid reduction of suicidal thoughts in major depression: A midazolam-controlled randomized clinical trial. Am J Psychiatry. 2018; 175(4): 327-35.

55. Phillips JL, Norris S, Talbot J, Birmingham M, Hatchard T, Ortiz A, et al. Single, Repeated, and Maintenance Ketamine Infusions for Treatment-Resistant Depression: A Randomized Controlled Trial. Am J Psychiatry. 2019; 176(5): 401-9.

56. Zheng W, Zhou Y-L, Liu W-J, Wang C-Y, Zhan Y-N, Li H-Q, et al. Investigation of medical effect of multiple ketamine infusions on patients with major depressive disorder. J Psychopharmacol. 2019; 33(4): 494-501.

57. Domany Y, Shelton RC, McCullumsmith CB. Ketamine for acute suicidal ideation. An emergency department intervention: A randomized, double-blind, placebo-controlled, proof-of-concept trial. Depress Anxiety. 2020; 37(3): 224-33.

58. Vollenweider FX, Leenders KL, Øye I, Hell D, Angst J. Differential psychopathology and patterns of cerebral glucose utilisation produced by $(\mathrm{S})$ - and (R)-ketamine in healthy volunteers using positron emission tomography (PET). Eur Neuropsychopharmacol. 1997; 7(1):25-38.

59. Oye I, Paulsen O, Maurset A. Effects of ketamine on sensory perception: evidence for a role of Nmethyl-D-aspartate receptors. J Pharmacol Exp Ther. 1992; 260(3): 1209 LP - 1213.

60. Kohrs R, Durieux ME. Ketamine: Teaching an Old Drug New Tricks. Anesth Analg. 1998; 87(5): 1186-93.

61. Singh JB, Fedgchin M, Daly E, Xi L, Melman C, De Bruecker G, et al. Intravenous Esketamine in Adult Treatment-Resistant Depression: A Double-Blind, Double-Randomization, Placebo-Controlled Study. Biol Psychiatry. 2015; 80(6): 424-31.

62. Daly EJ, Singh JB, Fedgchin M, Cooper K, Lim P, Shelton RC, et al. Efficacy and Safety of Intranasal Esketamine Adjunctive to Oral Antidepressant Therapy in Treatment-Resistant Depression. JAMA Psychiatry. 2018; 75(2): 139-48.

63. Canuso CM, Singh JB, Fedgchin M, Alphs L, Lane R, Lim P, et al. Efficacy and Safety of Intranasal Esketamine for the Rapid Reduction of Symptoms of Depression and Suicidality in Patients at Imminent Risk for Suicide: Results of a Double-Blind, Randomized, Placebo-Controlled Study. Am J Psychiatry. 2018; 175(7): 620-30.

64. Popova V, Daly EJ, Trivedi M, Cooper K, Lane R, Lim P, et al. Efficacy and Safety of Flexibly Dosed Esketamine Nasal Spray Combined With a Newly Initiated Oral Antidepressant in Treatment-Resistant Depression: A Randomized Double-Blind Active-Controlled Study. Am J Psychiatry. 2019; 176(6): 428-38.

65. Fedgchin M, Trivedi M, Daly EJ, Melkote R, Lane R, Lim P, et al. Efficacy and Safety of Fixed-Dose Esketamine Nasal Spray Combined With a New Oral Antidepressant in Treatment-Resistant Depression: Results of a Randomized, Double-Blind, Active-Controlled Study (TRANSFORM-1). Int J Neuropsychopharmacol. 2019; 22(10): 616-30.

66. Daly EJ, Trivedi MH, Janik A, Li H, Zhang Y, Li X, et al. Efficacy of Esketamine Nasal Spray Plus Oral Antidepressant Treatment for Relapse Prevention in Patients With Treatment-Resistant Depression. JAMA Psychiatry. 2019; 76(9): 893-903.

67. Correia-Melo FS, Leal GC, Vieira F, Jesus-Nunes AP, Mello RP, Magnavita G, et al. Efficacy and safety of adjunctive therapy using esketamine or racemic ketamine for adult treatment-resistant depression: A randomized, double-blind, non-inferiority study. J Affect Disord. 2020; 264: 527-34.

68. Wajs E, Aluisio L, Holder R, Daly EJ, Lane R, Lim P, et al. Esketamine Nasal Spray Plus Oral Antidepressant in Patients With Treatment-Resistant Depression. J Clin Psychiatry. 2020; 81(3): $19 \mathrm{~m} 12891$.

69. Fu D-J, Ionescu DF, Li X, Lane R, Lim P, Sanacora G, et al. Esketamine Nasal Spray for Rapid Reduction of Major Depressive Disorder Symptoms in Patients Who Have Active Suicidal Ideation With Intent. J Clin Psychiatry. 2020; 81(3): 4-5.

70. Ionescu DF, Fu D-J, Qiu X, Lane R, Lim P, Kasper S, et al. Esketamine Nasal Spray for Rapid Reduction of Depressive Symptoms in Patients With Major Depressive Disorder Who Have Active Suicide Ideation With Intent: Results of a Phase 3, Double-Blind, Randomized Study (ASPIRE II). Int J Neuropsychopharmacol. 2021; 24(1): 22-31. 